\title{
Methane and nitrous oxide retrievals from MIPAS-ENVISAT
}

\author{
J. Plieninger, T. von Clarmann, G. P. Stiller, U. Grabowski, N. Glatthor, S. Kellmann, A. Linden, F. Haenel, \\ M. Kiefer, M. Höpfner, A. Laeng, and S. Lossow \\ Karlsruhe Institute of Technology, Institute of Meteorology and Climate Research, Karlsruhe, Germany \\ Correspondence to: J. Plieninger (johannes.plieninger@kit.edu)
}

Received: 23 April 2015 - Published in Atmos. Meas. Tech. Discuss.: 28 July 2015

Revised: 21 October 2015 - Accepted: 30 October 2015 - Published: 5 November 2015

\begin{abstract}
We present the strongly revised IMK/IAA MIPAS-ENVISAT $\mathrm{CH}_{4}$ and $\mathrm{N}_{2} \mathrm{O}$ data products for the MIPAS full-resolution (versions V5H_CH4_21 and V5H_N2O_21) and for the reduced-resolution period (versions V5R_CH4_224, V5R_CH4_225, V5R_N2O_224 and V5R_N2O_225). These data sets cover both MIPAS measurement periods from June 2002 until March 2004 and from January 2005 to April 2012. Differences with older retrieval versions which are known to have a high bias are discussed. The usage of the HITRAN 2008 spectroscopic data set leads to lower values for both gases in the lower part of the profile. The improved correction of additive radiance offsets and handling of background radiance continua allows for aerosol contributions at altitudes in the upper stratosphere and above. These changes lead to more plausible values, both in the radiance offset and in the profiles of the continuum absorption coefficients. They also increase the fraction of converged retrievals. Some minor changes were applied to the constraint of the inverse problem, causing small differences in the retrieved profiles, mostly due to the relaxation of off-diagonal regularisation matrix elements for the calculation of jointly retrieved absorption coefficient profiles. Spectral microwindows have been adjusted to avoid areas with saturated spectral signatures. Jointly retrieving profiles of water vapour and nitric acid serves to compensate spectroscopic inconsistencies. We discuss the averaging kernels of the profiles and their vertical resolution. The latter ranges from 2.5 to $7 \mathrm{~km}$ for $\mathrm{CH}_{4}$, and from 2.5 to $6 \mathrm{~km}$ for $\mathrm{N}_{2} \mathrm{O}$ in the reducedresolution period. For the full-resolution period, the vertical resolution is in the order of 3 to $6 \mathrm{~km}$ for both gases. We find the retrieval errors in the lower part of the profiles mostly to be around $15 \%$ for $\mathrm{CH}_{4}$ and below $10 \%$ for $\mathrm{N}_{2} \mathrm{O}$. The errors
\end{abstract}

above 25 or $30 \mathrm{~km}$ increase to values between 10 and $20 \%$, except for $\mathrm{CH}_{4}$ from the reduced-resolution period, where the estimated errors stay below $15 \%$.

\section{Introduction}

The Michelson Interferometer for Passive Atmospheric Sounding (MIPAS, Fischer et al., 2008) is a Fourier transform spectrometer on board the Environmental Satellite (ENVISAT). This satellite was launched in March 2002 and operated by the European Space Agency (ESA) until April 2012, when it ceased all communication to ground. During that time, MIPAS measured atmospheric emission spectra in the infrared between 685 and $2410 \mathrm{~cm}^{-1}$ in limb geometry. There are two MIPAS measurement periods: during the fullresolution period from June 2002 until March 2004, the instrument measured with a theoretical spectral resolution of $0.025 \mathrm{~cm}^{-1}\left(0.0483 \mathrm{~cm}^{-1}\right.$ after a "Norton-Beer strong" apodisation; Norton and Beer, 1976). Due to a malfunction in the interferometer slide system, there is a data gap until January 2005 when the instrument recommenced measuring with a so-called reduced resolution ${ }^{1}$ of $0.0625 \mathrm{~cm}^{-1}$ $\left(0.121 \mathrm{~cm}^{-1}\right.$ after the apodisation). The instrument has been operated in several different measurement modes with different tangent altitude patterns. For this study, only spectra from the MIPAS nominal measurement mode have been used; this covers about $80 \%$ of the total measurement time. For the full-resolution period, one limb scan contains 17 different

\footnotetext{
${ }^{1}$ ESA uses the term "optimised resolution" for this period in their product names.
} 
Table 1. Data versions with temporal coverage and information for which the changes discussed in Sect. 3 were applied.

\begin{tabular}{|c|c|c|c|c|c|c|}
\hline Version names & Temp. coverage & $\begin{array}{l}\text { HITRAN } \\
2008\end{array}$ & $\begin{array}{l}\text { Improved continuum/ } \\
\text { and offset }\end{array}$ & $\begin{array}{c}\text { New } \\
\text { microwindows }\end{array}$ & $\begin{array}{c}\text { New } \\
\text { constraint }\end{array}$ & $\begin{array}{c}\text { Joint fit } \\
\mathrm{H}_{2} \mathrm{O} / \mathrm{HNO}_{3}\end{array}$ \\
\hline V5H_CH4_20 & Jun 2002-Mar 2004 & yes & yes & no & no & no \\
\hline V5H_N2O_20 & Jun 2002-Mar 2004 & yes & yes & no & no & no \\
\hline V5H_CH4_21 & Jun 2002-Mar 2004 & yes & yes & yes & yes & yes \\
\hline V5H_N2O_21 & Jun 2002-Mar 2004 & yes & yes & yes & yes & yes \\
\hline V5R_CH4_220 & Jan 2005-Apr 2011 & no & no & no & no & no \\
\hline V5R_N2O_220 & Jan 2005-Apr 2011 & no & no & no & no & no \\
\hline V5R_CH4_221 & May 2011-Apr 2012 & no & no & no & no & no \\
\hline V5R_N2O_221 & May 2011-Apr 2012 & no & no & no & no & no \\
\hline V5R_CH4_222 & Jan 2005-Apr 2011 & yes & yes & no & no & no \\
\hline V5R_N2O_222 & Jan 2005-Apr 2011 & yes & yes & no & no & no \\
\hline V5R_CH4_223 & May 2011-Apr 2012 & yes & yes & no & no & no \\
\hline V5R_N2O_223 & May 2011-Apr 2012 & yes & yes & no & no & no \\
\hline V5R_CH4_224 & Jan 2005-Apr 2011 & yes & yes & yes & yes & yes \\
\hline V5R_N2O_224 & Jan 2005-Apr 2011 & yes & yes & yes & yes & yes \\
\hline V5R_CH4_225 & May 2011-Apr 2012 & yes & yes & yes & yes & yes \\
\hline V5R_N2O_225 & May 2011-Apr 2012 & yes & yes & yes & yes & yes \\
\hline
\end{tabular}

spectra with tangent altitudes from 6 to $68 \mathrm{~km}$. A limb scan in the reduced-resolution period consists of 27 different spectra and their tangent altitudes are latitude-dependent. The lowest tangent altitude ranges from $6 \mathrm{~km}$ at the polar regions to $9 \mathrm{~km}$ at the equator and the highest tangent altitude increases from $70 \mathrm{~km}$ in polar regions to $73 \mathrm{~km}$ at the equator.

The processor developed at the Institute of Meteorology and Climate Research in cooperation with the Instituto de Astrofísica de Andalucía (CSIC) retrieves profiles of temperature and various trace gases. The retrieval of $\mathrm{CH}_{4}$ and $\mathrm{N}_{2} \mathrm{O}$ with this processor was first described in Glatthor et al. (2005) for the full-resolution period and in von Clarmann et al. (2009) for the reduced-resolution period.

Various studies showed $\mathrm{CH}_{4}$ and $\mathrm{N}_{2} \mathrm{O}$ profiles retrieved from MIPAS-ENVISAT to have a positive bias in the lower part of the profiles. In Glatthor et al. (2005) the largest $\mathrm{CH}_{4}$ and $\mathrm{N}_{2} \mathrm{O}$ values are compared to tropospheric climatological data and found to be $0.7 \mathrm{ppmv}$ (39\%) higher for $\mathrm{CH}_{4}$ and 80 ppbv ( $25 \%$ ) higher for $\mathrm{N}_{2} \mathrm{O}$. Höpfner et al. (2007) compared MIPAS full-resolution $\mathrm{CH}_{4}$ and $\mathrm{N}_{2} \mathrm{O}$ profiles, versions V3O_CH4_9 and V3O_N2O_9, to those measured by ACE-FTS in version 2.2. This study uses profiles measured during northern polar winter. Below 15 to $18 \mathrm{~km}$, MIPAS $\mathrm{CH}_{4}$ profiles showed a high bias of around $0.2 \mathrm{ppmv}(15 \%)$, while for $\mathrm{N}_{2} \mathrm{O}$ a MIPAS bias of around $25 \mathrm{ppbv}(10 \%)$ was found below 15 to $18 \mathrm{~km}$. Von Clarmann et al. (2009) state that the bias in the reduced-resolution period is smaller than in the full-resolution period, but still present. Laeng et al. (2015) did a detailed validation of MIPAS reduced-resolution V5R_CH4_222, comparing it to profiles from ACE-FTS, SCIAMACHY, HALOE, SOFIE, Mark IV balloon interfer- ometer and cryosampler in situ measurements. They found MIPAS profiles to be biased high below $25 \mathrm{~km}$ by about 0.2 ppmv (14\%).

The aim of this study has been the improvement of the MIPAS IMK/IAA $\mathrm{CH}_{4}$ and $\mathrm{N}_{2} \mathrm{O}$ products.

\section{General retrieval descriptions}

Here we discuss the latest retrieval setup of $\mathrm{CH}_{4}$ and $\mathrm{N}_{2} \mathrm{O}$. For the full-spectral-resolution period, this refers to data versions V5H_CH4_21 and V5H_N2O_21 and for the reduced-resolution period to data versions V5R_CH4_224, V5R_CH4_225, V5R_N2O_224 and V5R_N2O_225. For simplicity, in the following only the last part of the version code will be used. This simplification, however, is not applicable beyond this work because version identifiers are gas-specific. Versions 224 and 225 are almost identical. Version numbers are different only to guarantee complete traceability. The only technical difference is the source of the ECMWF analysis used to constrain the preceding temperature retrievals. This has no discernible effect on the $\mathrm{CH}_{4}$ and $\mathrm{N}_{2} \mathrm{O}$ profiles. Thus, we do not discuss these versions separately. The data sets of these versions are disjoint in a sense that one observation is either 224 or 225 . Thus the data sets are complementary. For one level-1 product, either a 224 or a 225 product exists, but not both. All this applies also to older pairs of versions i.e. 220 and 221, as well as to 222 and 223. Table 1 offers an overview of the data versions discussed.

Volume mixing ratios (vmr) of $\mathrm{CH}_{4}$ and $\mathrm{N}_{2} \mathrm{O}$ are retrieved in MIPAS channel B in several microwindows between 1220 and $1320 \mathrm{~cm}^{-1}$ in the P-branch of the $v_{4}$ band of $\mathrm{CH}_{4}$ with 
the MIPAS-ENVISAT data processor developed at IMK and IAA (von Clarmann et al., 2003). The level $1 \mathrm{~b}$ data used for the retrievals were from version MIPAS/5.02-5.06.

For each MIPAS limb scan, profiles of $\mathrm{CH}_{4}$ and $\mathrm{N}_{2} \mathrm{O}$ are retrieved. Since there are strong cross-interferences between the $\mathrm{CH}_{4}$ and the $\mathrm{N}_{2} \mathrm{O}$ lines, both species are retrieved simultaneously in one retrieval step to minimise mutual error propagation. In addition, mixing ratios of the interfering species $\mathrm{HNO}_{3}$ and $\mathrm{H}_{2} \mathrm{O}$ are jointly fitted to improve the spectral residual. The profiles of temperature, pressure and ozone as well as the spectral shift correction and the tangent altitudes are known from previous retrieval steps and are not treated as variables in the $\mathrm{CH}_{4}$ and $\mathrm{N}_{2} \mathrm{O}$ retrieval, but their retrieved values are used within the radiative transfer calculations. An additive radiance offset correction is retrieved for each microwindow. It is constant for all tangent heights. Additionally, for each microwindow, continuum absorption coefficient profiles are retrieved that account for continuum spectral contributions of atmospheric aerosol, uncertainties in the modelling of the continua of $\mathrm{O}_{3}, \mathrm{H}_{2} \mathrm{O}$ and $\mathrm{N}_{2}$ and contributions of distant lines which sum up to a quasi-continuum (von Clarmann et al., 2003).

A first-order Tikhonov finite differences constraint (e.g. Tikhonov, 1963; Steck and von Clarmann, 2001) is used to fight ill-posedness and to reduce vertical oscillations. The a priori profiles for both gases are zero. Therefore, not the mixing ratios themselves, but differences between adjacent profile values with respect to the a priori profile are constrained. Since the a priori profile is chosen all zero, this type of regularisation acts as a smoothing constraint. For methane, above $70 \mathrm{~km}$ a diagonal element in the regularisation matrix is used additionally. It pulls the profile in that height region towards zero. The regularisation matrix entries related to the continuum absorption coefficient contain some off-diagonal elements to prevent neighbouring microwindows from differing too much.

The retrieval is done on a fine vertical grid with a spacing of $1 \mathrm{~km}$ between 4 and $70 \mathrm{~km}$. Above that range, the grid gets coarser and consists of the following grid points: 75,80 , $85,90,100$ and $120 \mathrm{~km}$. Since not the entire altitude range is covered by measurements, some data points do not represent the real atmosphere at the respective altitude. Hence we recommend the applications of two altitude-dependent filter criteria: first, to neglect profile points where the diagonal element of the averaging kernel is less than 0.03 , and second, to discard points where the visibility flag is "false". The latter indicates that MIPAS has not seen the atmosphere at respective altitudes.

The retrieval setup version 2 for the full-resolution spectra is an adaption of the reduced-resolution spectra setup 224 and 225. All changes described in Sect. 3 are applied to these data versions as well. The only difference is a slightly different selection of the spectral microwindows.

\section{Changes in the retrieval setup}

As mentioned in the introduction, the main drawback of previous data versions was the high bias of $\mathrm{CH}_{4}$ and $\mathrm{N}_{2} \mathrm{O}$ below $25 \mathrm{~km}$. In order to improve the data, a number of major modifications in the retrieval setup were adopted. To make our data traceable, all modifications since versions 220 and 221 are reported and discussed in the following.

The first part (Sects. 3.1 and 3.2) deals with the changes which led to the data product versions 222 and 223. The second part (Sects. 3.3 to 3.5) explains the further changes which were included in the current product versions 224 and 225. In Table 1 the included changes are listed for each data version.

To illustrate the influence of the individual changes a test data set of 110 orbits from the reduced-resolution measurement period with 10439 limb scans is used. These spectra were measured between 5 June and 18 August 2010. Figure 1 shows the zonal mean vmr distributions for this data set.

Almost all the changes implemented in the 224 and 225 setup for the reduced-resolution spectra have been included in the new 21 setup for the full-resolution spectra as well. Only the selection of the spectral microwindows is slightly different. A data set of 1054 measurements from 16 orbits between 10 January and 20 February 2004 was calculated to investigate this new retrieval setup. In Fig. 2 the latitude-dependent mean vmr profiles for those calculations are shown.

\subsection{Usage of HITRAN 2008}

Previous retrievals of $\mathrm{CH}_{4}$ and $\mathrm{N}_{2} \mathrm{O}$ (up to versions 220 and 221) have relied on the HITRAN 2000 spectroscopic data set with updates from 2001 for $\mathrm{N}_{2} \mathrm{O}$ and HITRAN 2004 for $\mathrm{CH}_{4}$. The spectroscopic data sets of $\mathrm{CH}_{4}$ and $\mathrm{N}_{2} \mathrm{O}$ received an update in the HITRAN 2008 release (Rothman et al., 2009). Hence in the new $\mathrm{CH}_{4}$ and $\mathrm{N}_{2} \mathrm{O}$ retrieval setup, these new line data sets have been used. For $\mathrm{CH}_{4}$ all the differences in the spectroscopic data set are described in Rothman et al. (2009, and references therein). For $\mathrm{N}_{2} \mathrm{O}$ the updates in HITRAN 2008 have not affected the spectral region of the MIPAS retrieval. In the HITRAN 2004 version, many updates were introduced of the $\mathrm{N}_{2} \mathrm{O}$ spectroscopy over the HITRAN 2000/2001 data set which had previously been used by the MIPAS retrieval. Almost the entire data set has been revised; details can be found in Rothman et al. (2005, and references therein).

In Fig. 3 the influence of the usage of the updated spectroscopic data set is presented. Areas where the new spectroscopy leads to higher mixing ratios are red; those where it produces lower mixing ratios are blue. Both in $\mathrm{CH}_{4}$ and $\mathrm{N}_{2} \mathrm{O}$, the mixing ratios are smaller in the lower part of the measured profiles. For $\mathrm{CH}_{4}$ the main changes are below $20 \mathrm{~km}$ in the tropics and below $15 \mathrm{~km}$ in the polar regions. The dif- 

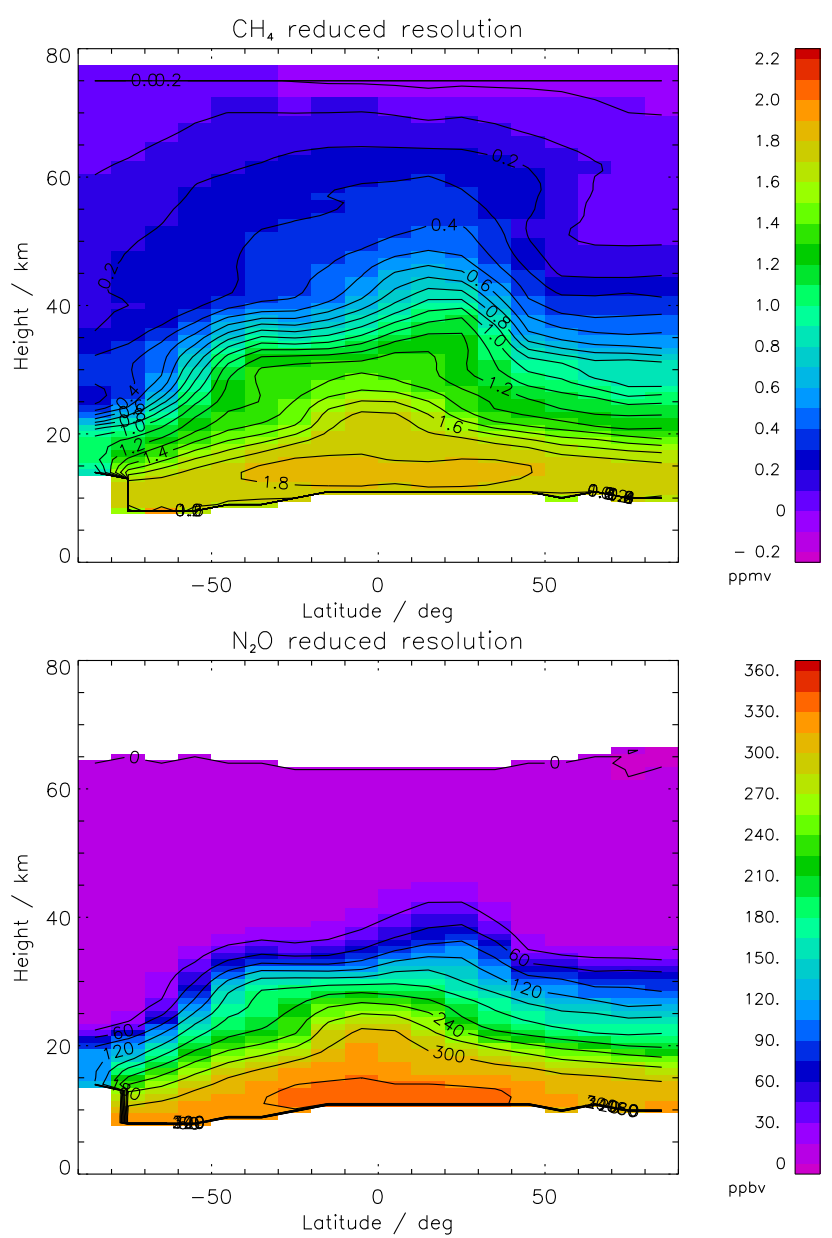

Figure 1. Zonal mean distributions for reduced-resolution spectra, measured between 5 June and 18 August 2010. The black lines are the interpolated isopleths. White areas show regions with no valid data at all. The upper panel shows results for $\mathrm{CH}_{4}$ (version V5R_CH4_224); the lower panel shows results for $\mathrm{N}_{2} \mathrm{O}$ (version V5R_N2O_224).

ferences are most pronounced in the troposphere at the lower boundary of the data product, where new spectroscopic data lead to values of up to $0.18 \mathrm{ppmv}$ lower than the old ones. These findings agree with Alvarado et al. (2015) who examined the influence of the HITRAN 2008 spectroscopy on the $\mathrm{CH}_{4}$ profiles retrieved from the NASA AURA Tropospheric Emission Spectrometer (TES, Beer et al., 2001) and found the values to be lower with the new data set. The $\mathrm{N}_{2} \mathrm{O}$ profiles with the HITRAN 2008 spectroscopy show smaller values up to almost $35 \mathrm{~km}$. Only the lowermost part of the valid data has a difference of less than -10 ppbv, the minimum in differences is -19 ppbv. The main differences in the retrieved $\mathrm{CH}_{4}$ and $\mathrm{N}_{2} \mathrm{O}$ result from updates of spectroscopic parameters for lines already existing in the database. Only very small differences between the old and new spectroscopy can possibly be attributed to new lines added within the used microwindows.
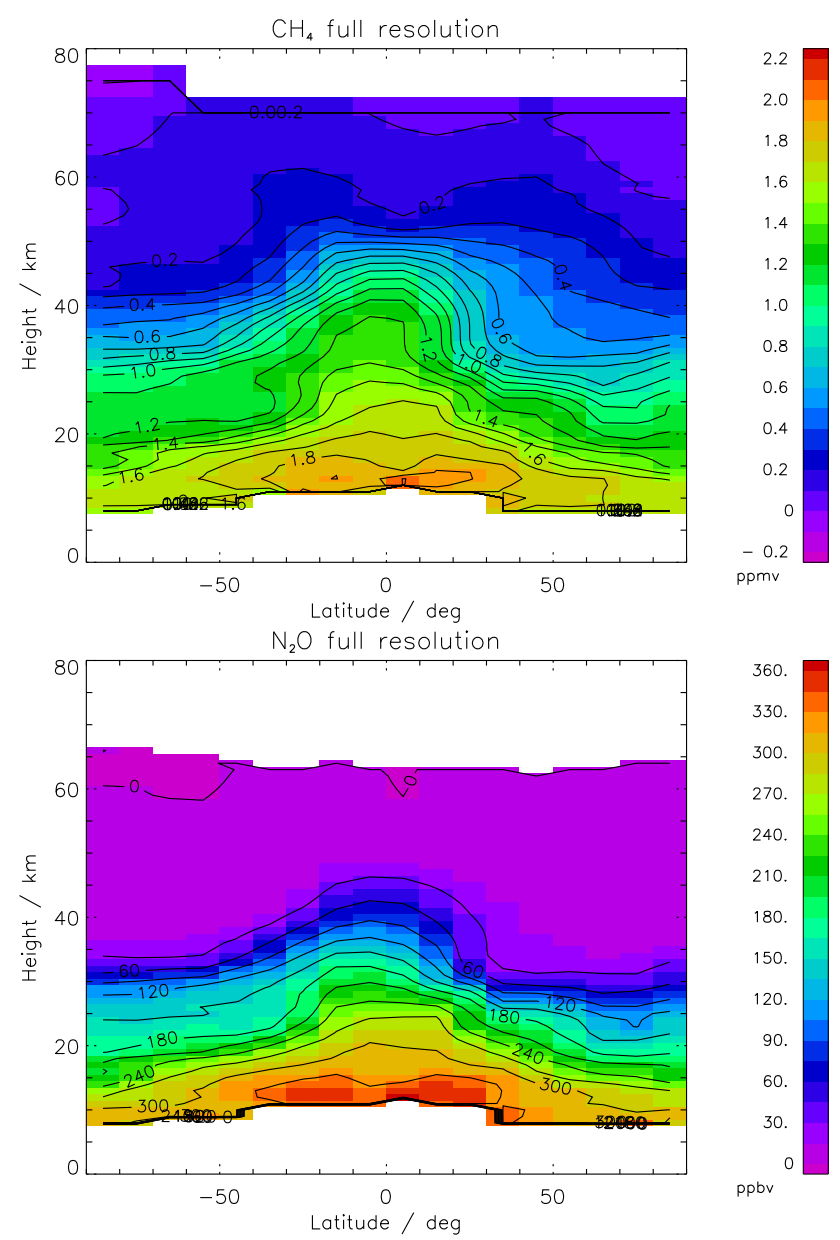

Figure 2. As Fig. 1, but for full-resolution spectra, measured between 10 January and 20 February. The upper panel shows results for $\mathrm{CH}_{4}$ (version V5H_CH4_21); the lower panel shows results for $\mathrm{N}_{2} \mathrm{O}$ (version V5H_N2O_21).

To determine, whether the changes of the profiles are due to either the spectroscopic changes of $\mathrm{CH}_{4}$ or $\mathrm{N}_{2} \mathrm{O}$, retrievals where for only one of the gases an updated spectroscopy was used, were carried out. It turned out, that the changes in $\mathrm{CH}_{4}$ are mostly due to the changes in the $\mathrm{CH}_{4}$ spectroscopy, and to a smaller extent to changes in the $\mathrm{N}_{2} \mathrm{O}$ spectroscopic data set. The changes in $\mathrm{N}_{2} \mathrm{O}$ profiles are mostly due to the changes in the $\mathrm{N}_{2} \mathrm{O}$ spectroscopy, but the larger changes at the very lower boundary in southern latitudes are due to the updates of the $\mathrm{CH}_{4}$ spectroscopy.

\subsection{Radiometric offset and continuum contributions}

For the data versions 220 and 221 the continuum absorption coefficient was fitted up to an altitude of $32 \mathrm{~km}$, which was the original suggestion of von Clarmann et al. (2003) for the retrieval of temperature. However, in some publications (e.g. Neely III et al., 2011; Bardeen et al., 2008) relevant aerosol abundances above that altitude are discussed. To 

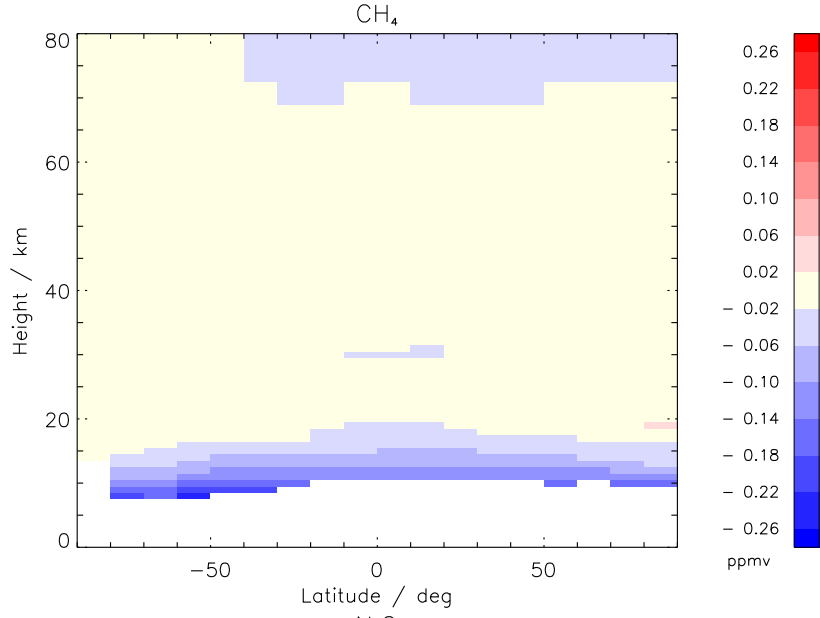

$\mathrm{N}_{2} \mathrm{O}$

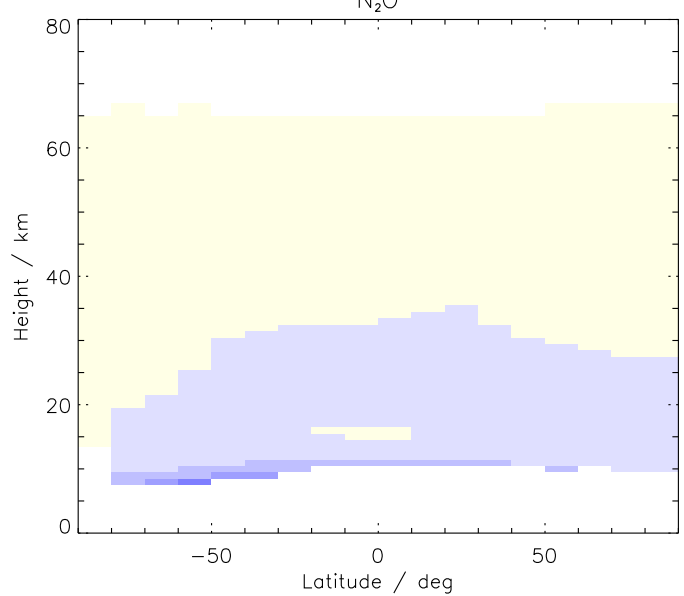

45.
39.
33.
27.
21.
15.
9.
3.
$-\quad 3$.
$-\quad 9$.
-15.
-21.
-27.
-33.
-39.
-45.
ppbv

Figure 3. Zonal mean difference distributions. Difference calculation with HITRAN 2008 spectroscopy of $\mathrm{CH}_{4}$ and $\mathrm{N}_{2} \mathrm{O}$ minus calculation with older spectroscopic data sets (for details see text). The upper panel shows results for $\mathrm{CH}_{4}$; the lower panel shows results for $\mathrm{N}_{2} \mathrm{O}$.

account for contributions from particles in this altitude range, we extended the upper boundary for the fit of the continuum absorption coefficient to $60 \mathrm{~km}$.

The residual radiance offset in versions 220 and 221 has been fitted independently for each individual tangent height. In combination with the fitting of the continuum absorption coefficient, this leads to an ill-posed inverse problem, where the contributions of both these variables can hardly be distinguished: continuum absorption coefficients that are too high can nearly compensate radiance corrections that are too low and vice versa. This leads to linearly dependent rows in the Jacobians of the retrieval. Thus, increasing the altitude range for the fit of the continuum absorption coefficient alone leads to even bigger oscillations. To avoid these instabilities, we now use a constant additive radiative offset over all tangent heights, a hard constraint of the radiance offset which IMK/IAA retrievals of most other species had already applied. This approach avoids any oscillating compensations
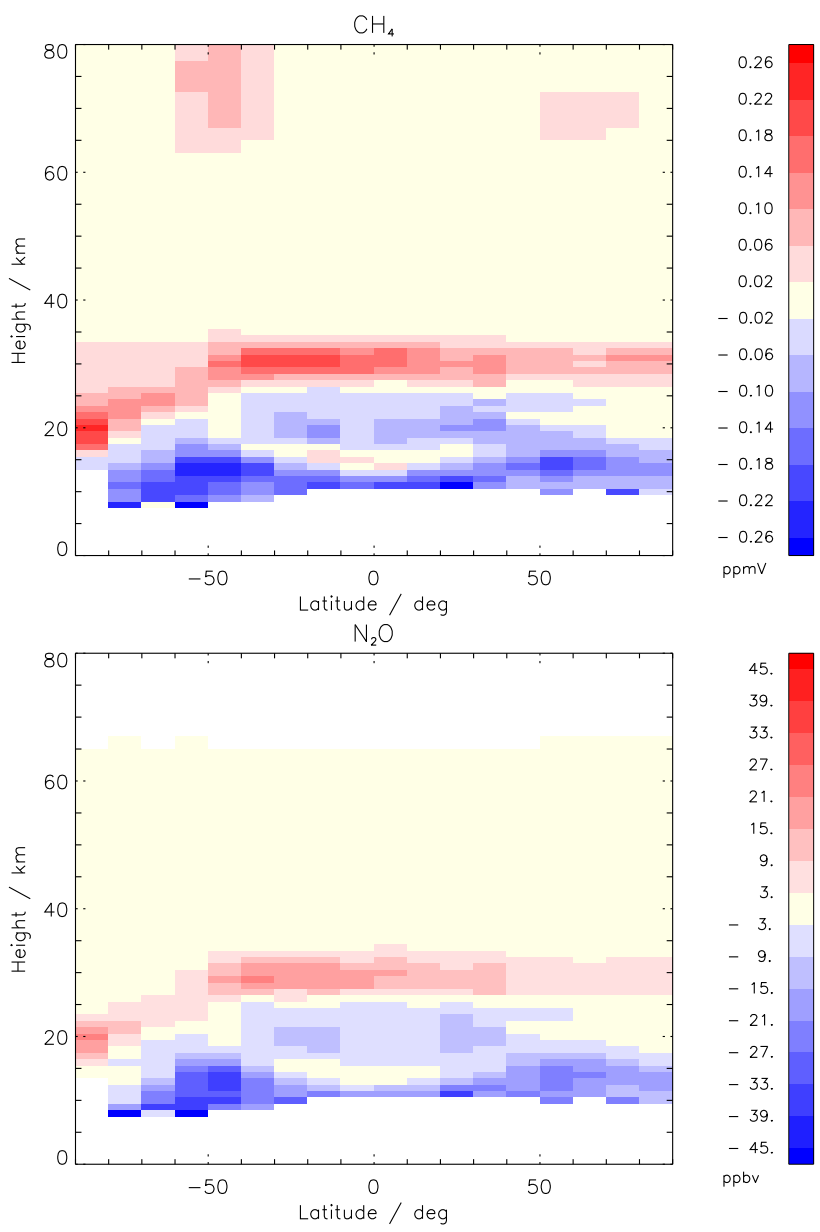

Figure 4. As Fig. 3, but difference retrieval with new offset and continuum setup minus reference with old setup.

between radiometric offset and the continuum absorption coefficient and leads to smoother profiles of the latter. Convergence does slightly improve. Instead of 10378, now 10403 of a total of 10439 cases do converge. The scientific analysis of the origin of the retrieved background radiation, probably aerosols, remains to be done.

The degrees of freedom (Rodgers, 2000) both in the profiles of methane and nitrous oxide prove to increase slightly (by $3.9 \%$ for $\mathrm{CH}_{4}$, by $5.9 \%$ for $\mathrm{N}_{2} \mathrm{O}$ ). The difference between the retrieval with constant radiometric offset and continuum absorption coefficient fitted up to $60 \mathrm{~km}$ and the setup versions 220 and 221 is shown in Fig. 4. Both the volume mixing ratios of $\mathrm{CH}_{4}$ and $\mathrm{N}_{2} \mathrm{O}$ are decreased in the altitude range below $20 \mathrm{~km}$. Hence the continuum handling in the old setup led to an effect of downward error propagation and to higher values in these altitude regions. Both gases show an increase at roughly $30 \mathrm{~km}$ (in the southern polar regions this feature is at slightly lower altitudes). 


\subsection{Constraint}

The IMK/IAA $\mathrm{CH}_{4}$ and $\mathrm{N}_{2} \mathrm{O}$ retrievals use an altitudedependent Tikhonov-like smoothing constraint based on squared first-order finite difference matrices $\mathbf{L}_{1}$. Up to data versions 222 and 223 the altitude dependence was implemented as suggested by Steck and von Clarmann (2001). This constraint has been replaced by a constraint using a regularisation matrix $\mathbf{R}=\mathbf{L}_{1}^{T} \mathbf{A} \mathbf{L}_{1}+\mathbf{D}$, where $\mathbf{A}$ is a diagonal matrix controlling the altitude dependence of the constraint and $\mathbf{D}$ is zero except for some diagonal entries above $70 \mathrm{~km}$ (increasing with height) affecting methane only. At those altitudes, they pull the profile of methane towards the a priori which is zero. It is introduced because otherwise the retrieved methane profiles tend to show negative values above $70 \mathrm{~km}$, even in the zonal averages, which clearly is an artefact. Adding the diagonal element in the constraint leads to values close to zero. However,some slightly negative retrieved volume mixing ratios still remain in the zonal mean at $75 \mathrm{~km}$. Our analysis shows that the introduction of the diagonal element to the regularisation matrix $\mathbf{R}$ does not alter the volume mixing ratio profiles below that altitude. Hence these physically still erroneous values above do not affect the quality of the data product below.

A further change was applied with respect to the offdiagonal matrix elements which pull the continuum absorption coefficient profiles of neighbouring microwindows towards each other. These entries have been considerably reduced, which allows a more pronounced spectral structure of the background emission. This leads to slightly decreased values of $\mathrm{CH}_{4}$ at $20 \mathrm{~km}$ altitude and $\mathrm{N}_{2} \mathrm{O}$ below $15 \mathrm{~km}$. This is shown in Fig. 5, where the difference between the calculations with the new constraint setup minus those with the old setup is plotted. The degrees of freedom of $\mathrm{CH}_{4}$ were reduced by 0.25 and of $\mathrm{N}_{2} \mathrm{O}$ were increased by 0.25 , while the continuum absorption coefficient profiles gained about 14 degrees of freedom.

\subsection{Spectral microwindows}

Usually, high-resolution spectroscopy retrievals do not invert the entire measured spectra, but only narrow spectral windows containing lines of the target species, so-called microwindows (e.g. von Clarmann and Echle, 1998). The selection of these spectral microwindows has been changed compared to previous data versions. The microwindows from $1270 \mathrm{~cm}^{-1}$ towards higher wavenumbers have been restricted to higher altitudes because the spectra in that region were saturated around the position of the line centres below. Additional microwindows at 1225,1239 and $1245 \mathrm{~cm}^{-1}$ and in the range of 1257 to $1270 \mathrm{~cm}^{-1}$ have been introduced to compensate the related loss of information at the higher wavenumbers and to stabilise the joint fit of $\mathrm{H}_{2} \mathrm{O}$ (see Sect. 3.5).
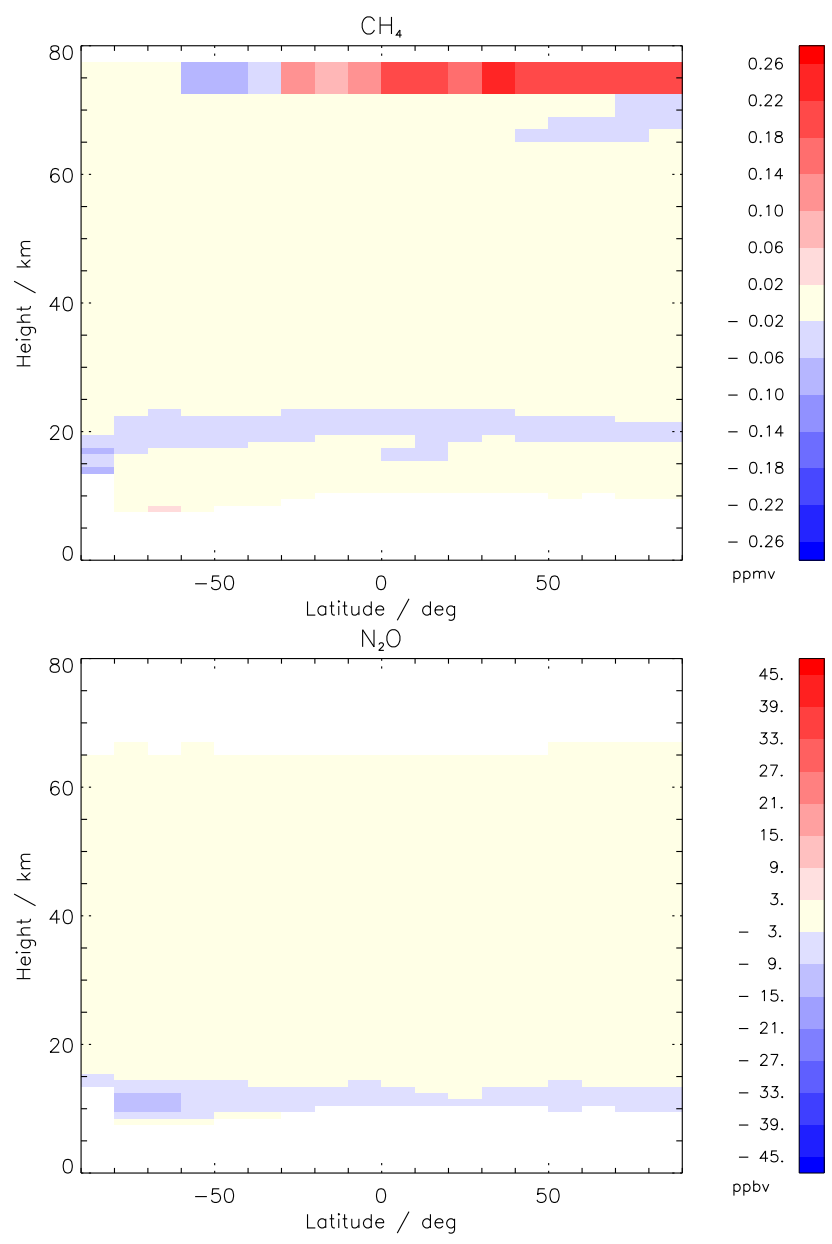

Figure 5. As Fig. 3, but difference retrieval with Tikhonov constraint and relaxed constraint between neighbouring microwindows minus reference with old setup.

The selection of the microwindows used in versions 220 , 221, 222 and 223 are compared to those of versions 224 and 225 in Fig. 6.

Figure 7 shows the impact of the new microwindow selection on the mean profiles of $\mathrm{CH}_{4}$ and $\mathrm{N}_{2} \mathrm{O}$. For both species the volume mixing ratios below $20 \mathrm{~km}$ did decrease at all latitudes. In the subtropics and tropics between 20 and $30 \mathrm{~km}$, an increase in volume mixing ratio can be observed. Convergence of the iterative retrieval was achieved in a larger number of cases: instead of 10399 in setup versions 222 and 223, now 10421 measurements (of 10439 total) converged. The changes in the microwindows led to a slight decrease (by $6 \%$ ) in the root-mean-square difference between the measured and the best-fit spectra (RMS) and to an increase in degrees of freedom for methane (by $2.3 \%$ ). For $\mathrm{N}_{2} \mathrm{O}$ the degrees of freedom dropped slightly (by $2.7 \%$ ). 

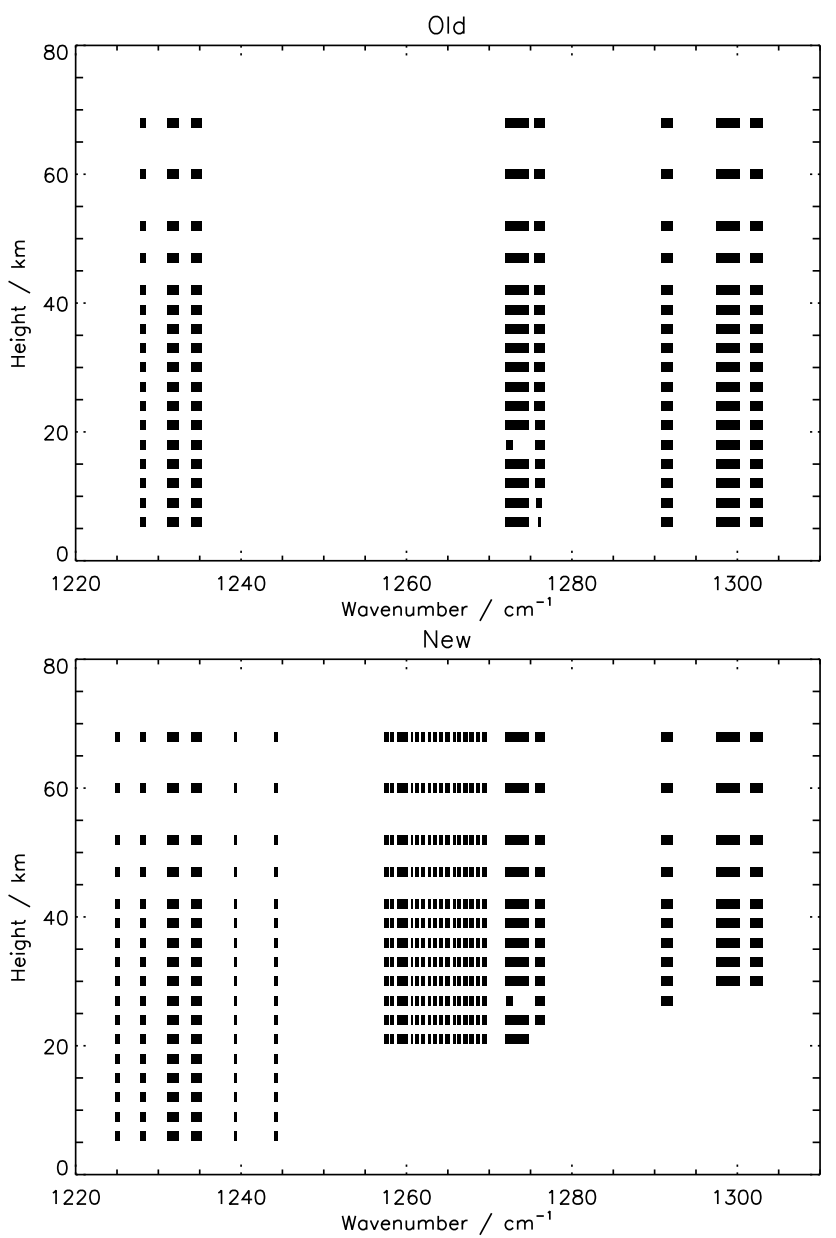

Figure 6. Selected microwindows of the setups V5R_CH4_220, V5R_CH4_221, V5R_N2O_220 and V5R_N2O_221 as well as V5R_CH4_222, V5R_CH4_223, V5R_N2O_222 and V5R_N2O_223 (upper panel) and V5R_CH4_224, V5R_CH4_225, V5R_N2O_224 and V5R_N2O_225 (lower panel) as a function of wavenumbers and tangent altitudes. The microwindows are marked as black patches.

\subsection{Joint fit of water vapour and nitric acid}

To improve the fit and to reduce the systematic residuals in the best fit spectra, the mixing ratios of $\mathrm{HNO}_{3}$ and $\mathrm{H}_{2} \mathrm{O}$ are retrieved additionally to $\mathrm{CH}_{4}$ and $\mathrm{N}_{2} \mathrm{O}$, continuum absorption coefficient and radiometric offset (joint fit approach) in the latest versions. Versions 222 and 223 and earlier versions used the volume mixing ratio profiles which were retrieved in previous retrieval steps as constant parameters. The new approach can compensate for any spectroscopic inconsistency between the spectral microwindows of the specific gas retrievals (in this case $\mathrm{HNO}_{3}$ and $\mathrm{H}_{2} \mathrm{O}$ ) and those used in the setup for the retrieval of $\mathrm{CH}_{4}$ and $\mathrm{N}_{2} \mathrm{O}$.

The influence of the joint fit of $\mathrm{HNO}_{3}$ and $\mathrm{H}_{2} \mathrm{O}$ on the results for $\mathrm{CH}_{4}$ and $\mathrm{N}_{2} \mathrm{O}$ is shown in Fig. 8. Both the profiles of $\mathrm{CH}_{4}$ and $\mathrm{N}_{2} \mathrm{O}$ are moderately reduced below $20 \mathrm{~km}$ altitude.
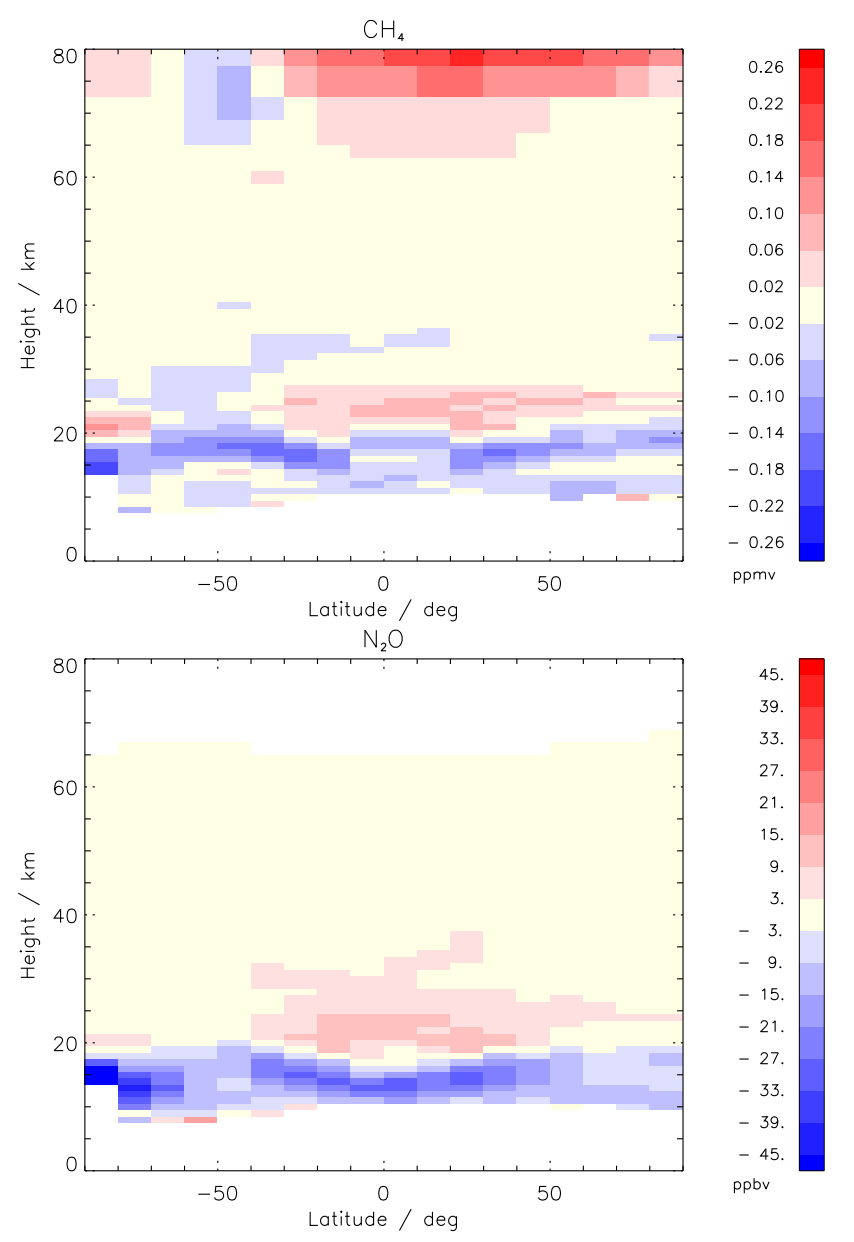

Figure 7. As Fig. 3, but difference retrieval with new selection of microwindows minus reference with old setup.

The RMS does hardly change and the degrees of freedom for $\mathrm{CH}_{4}$ and $\mathrm{N}_{2} \mathrm{O}$ decrease slightly.

\section{Retrieval characterisation}

The $\mathrm{CH}_{4}$ and $\mathrm{N}_{2} \mathrm{O}$ profiles from the reduced-resolution period derived with the new setup versions 224 and 225 show significantly reduced oscillations in polar regions compared to those retrieved with versions 222 and 223. The fraction of converged retrievals of the entire data set has significantly increased compared to the older versions. With the new setup, $0.37 \%$ of the retrievals did not converge, compared to $1.02 \%$ of the profiles with setup versions 220 and 221, and $1.27 \%$ with versions 222 and 223 .

The mean vertical resolution of the test data set (see Sect. 3) is shown in Fig. 9 both for $\mathrm{CH}_{4}$ and $\mathrm{N}_{2} \mathrm{O}$. The values are full widths at half maximum of the rows of the averaging kernels. For $\mathrm{CH}_{4}$ a resolution of about 2.5 to $7 \mathrm{~km}$ can be obtained below $60 \mathrm{~km}$. Above this level, it becomes rather coarse, due to the larger tangent height spacing. At altitudes 

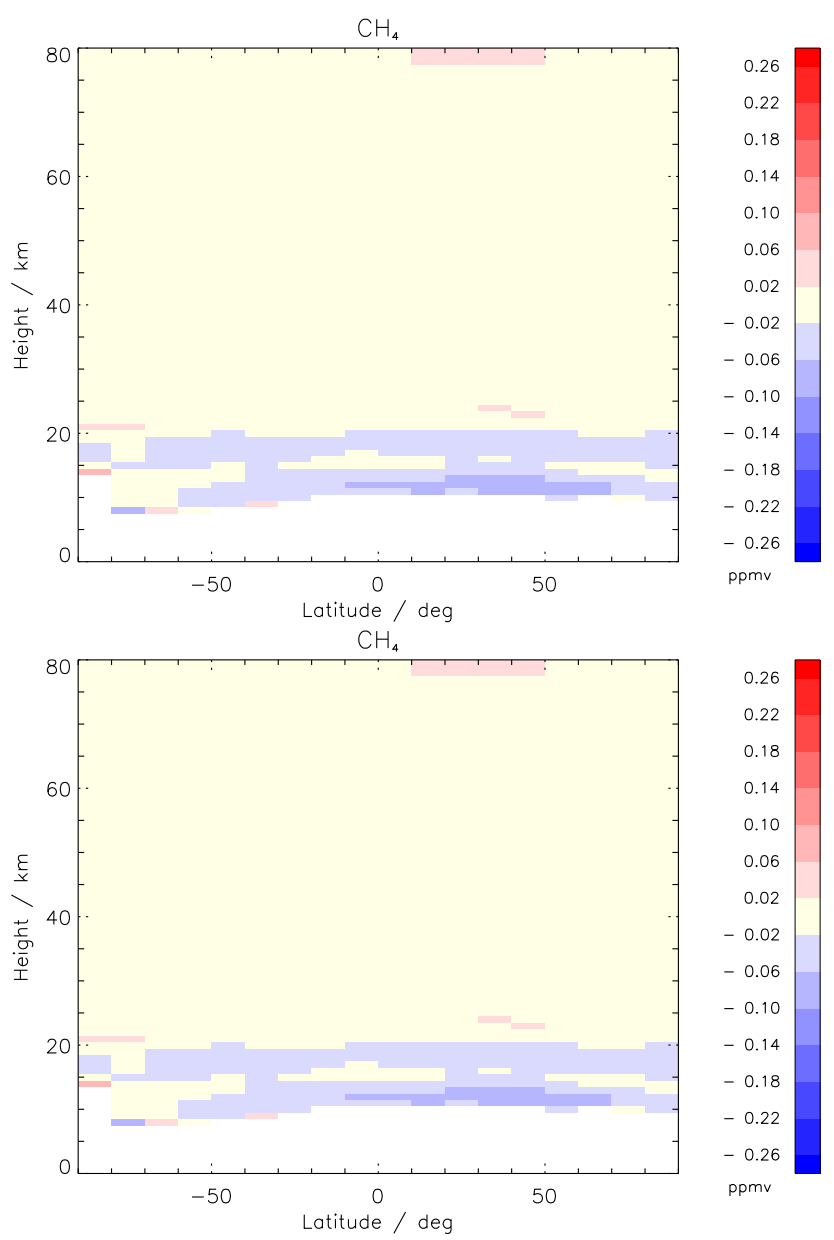

Figure 8. As Fig. 3, but difference retrieval with joint fit of $\mathrm{HNO}_{3}$ and $\mathrm{H}_{2} \mathrm{O}$ minus reference with old setup.

below $20 \mathrm{~km}$ there is a slightly degraded resolution. The best resolved part of the profile is the altitude range between 25 and $35 \mathrm{~km}$, where the resolution reaches up to $2.2 \mathrm{~km}$. $\mathrm{N}_{2} \mathrm{O}$ is resolved well between $20 \mathrm{~km}$ ( $15 \mathrm{~km}$ in mid-latitudes) and $50 \mathrm{~km}$, where the resolution is about 2.5 to $6 \mathrm{~km}$. Above this range the volume mixing ratios are too small to allow for a good signal in the spectra. For both gases the mid-latitude regions have a better resolution than the tropical or polar areas. This is due to the colder tropopause in the latter regions, which produces lower emissions and hence a weaker signal.

In Fig. 10 a subset of the averaging kernel for a sample profile is shown. This reduced-resolution scan was measured in orbit 43202 at $39.4^{\circ} \mathrm{N}, 78.9^{\circ} \mathrm{E}$ on 5 June 2010 , 05:02:29 UTC. The plot shows the rows of the averaging kernel: each black cross on one curve denotes the nominal altitude of the related averaging kernel. The rows of the averaging kernels represent the weights of the true atmospheric states at various altitudes in the retrieval at the nominal altitude. In the case of $\mathrm{CH}_{4}$, for most of the curves the black cross lies at the maximum position, i.e. the atmospheric state
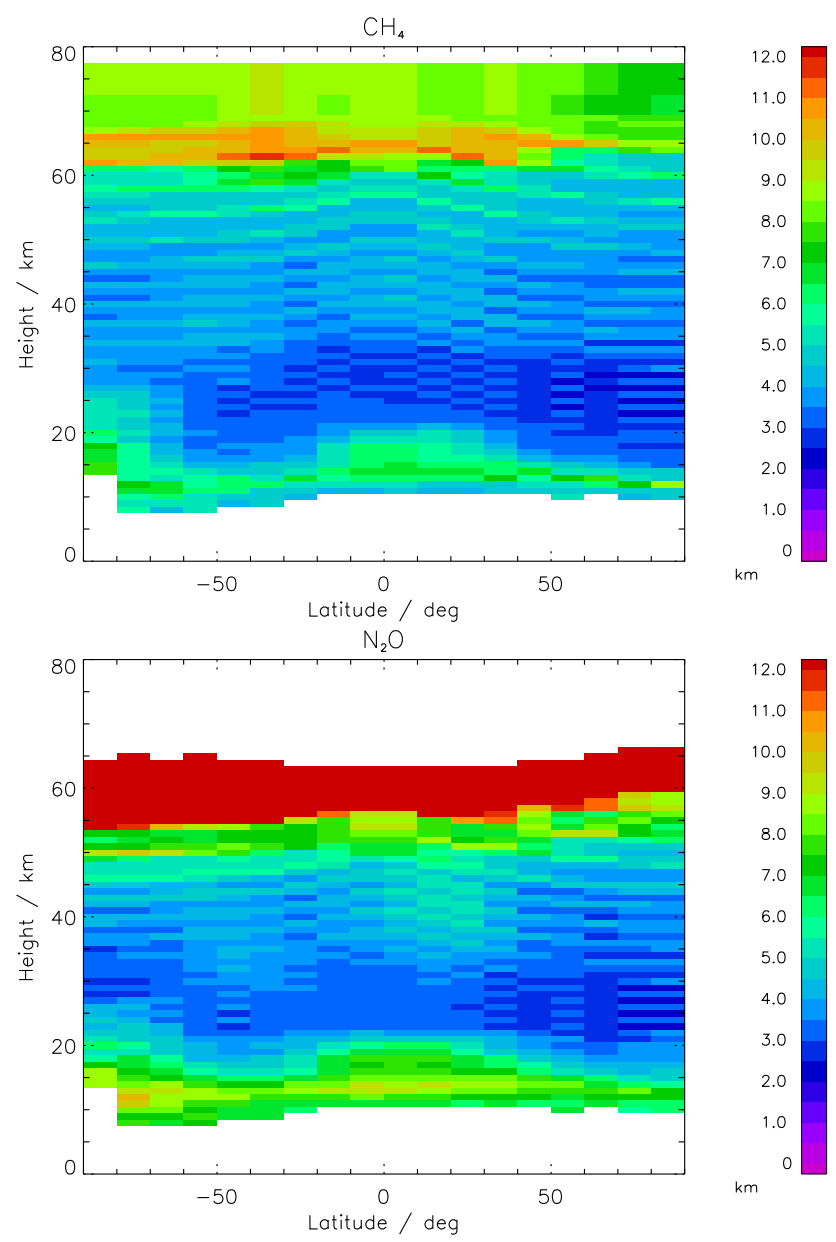

Figure 9. Mean vertical resolution in km for profiles from reducedresolution spectra (versions V5R_CH4_224 and V5R_N2O_224). The upper panel shows results for $\mathrm{CH}_{4}$; the lower panel shows results for $\mathrm{N}_{2} \mathrm{O}$.

at a certain altitude has the largest impact on a retrieved value in the same grid height. The curves are roughly symmetric to this point in shape. This allows a straightforward interpretation of the retrieved profiles. Above $55 \mathrm{~km}$ and below $15 \mathrm{~km}$, the curves do not always have their maximum on the nominal grid point and/or are asymmetric in shape. Without considering the averaging kernels, this can cause biases, and thus, interpretation of the retrieved profile should be conducted more carefully. The dashed-dotted blue line gives the integral of the averaging kernel rows. Due to the Tikhonov-type regularisation, the integral values are around 1 below $60 \mathrm{~km}$. Above $60 \mathrm{~km}$ they decline due to the diagonal term in the regularisation matrix, indicating that some of the information for these altitudes is not based on the measurement.

The lower panel of Fig. 10 shows the averaging kernels for the retrieval of $\mathrm{N}_{2} \mathrm{O}$ for the same measurement. Roughly symmetric curves can be found between 20 and $50 \mathrm{~km}$. All the information for the retrieved values above $50 \mathrm{~km}$ are almost entirely dependent on the values below. Outside this 

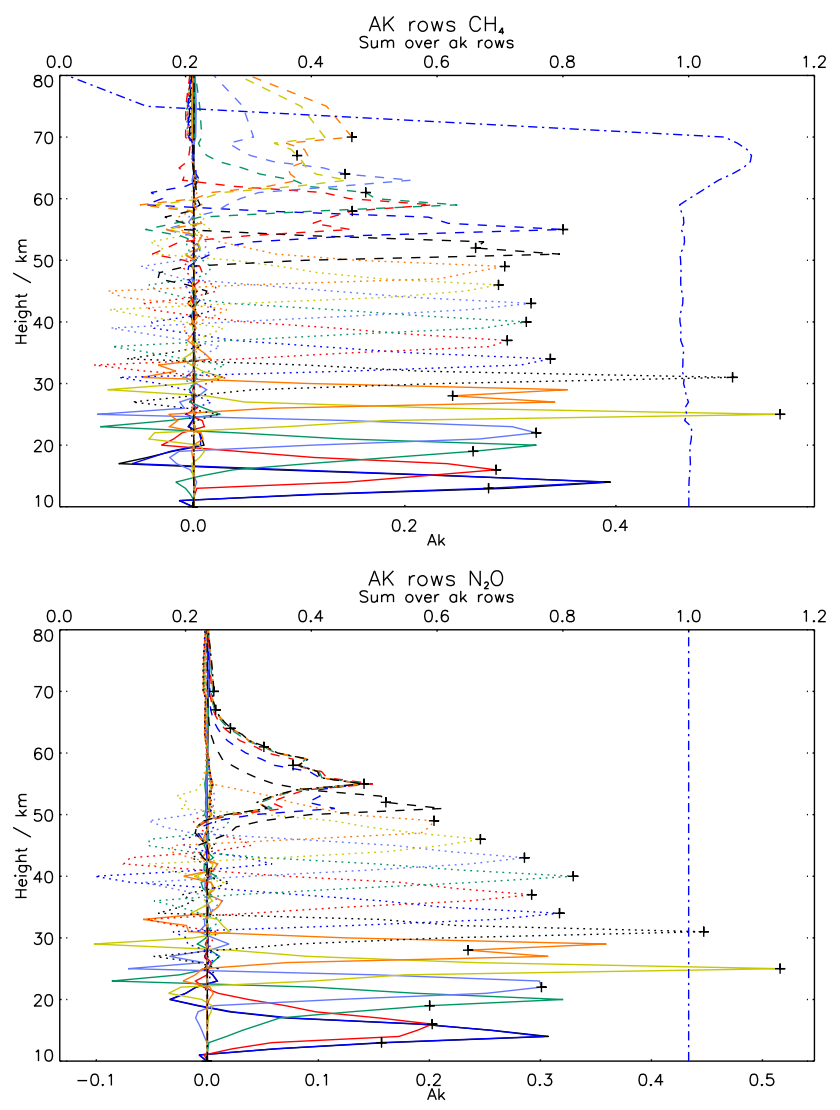

Figure 10. Selected rows of the averaging kernel matrix for the measurement in orbit 43202 at $39.4^{\circ} \mathrm{N}, 78.9^{\circ} \mathrm{E}$ on 5 June 2010 , 05:02:29 UTC (derived from reduced-resolution spectra, version V5R_CH4_224). The black crosses highlight the diagonal terms of the averaging kernel matrix. The blue dashed-dotted line gives the integral value of the rows (upper axis). The upper panel shows results for $\mathrm{CH}_{4}$ and the lower panel shows results for $\mathrm{N}_{2} \mathrm{O}$.

range the data without explicit consideration of the averaging kernels are prone to misinterpretation. The integrals of the averaging kernel rows are 1 at all altitudes, since there are no diagonal elements in the regularisation matrix.

Along with the retrieval, for each profile the impact of the instrument noise on the retrieved profile is calculated as a routine data product. However there are various additional error sources which have to be considered. These errors have been estimated for certain example profiles. The following errors have been assumed: for the uncertainty of the line of sight (los) $0.15 \mathrm{~km}$ vertical pointing (von Clarmann et al., 2003); for the spectral shift $0.005 \mathrm{~cm}^{-1}$; for the instrumental calibration error (gain) $1 \%$ (Kleinert et al., 2007); for the instrumental line shape error (ils) $3 \%$ (F. Hase, personal communication, 2015); and for the temperature gradient in latitudinal direction $0.01 \mathrm{~K} \mathrm{~km}^{-1}$ (constant with respect to altitude). The spectroscopic errors were extracted from the HITRAN database (Rothman et al., 2009), with a correction of the actual line intensity in dependence of the rotational
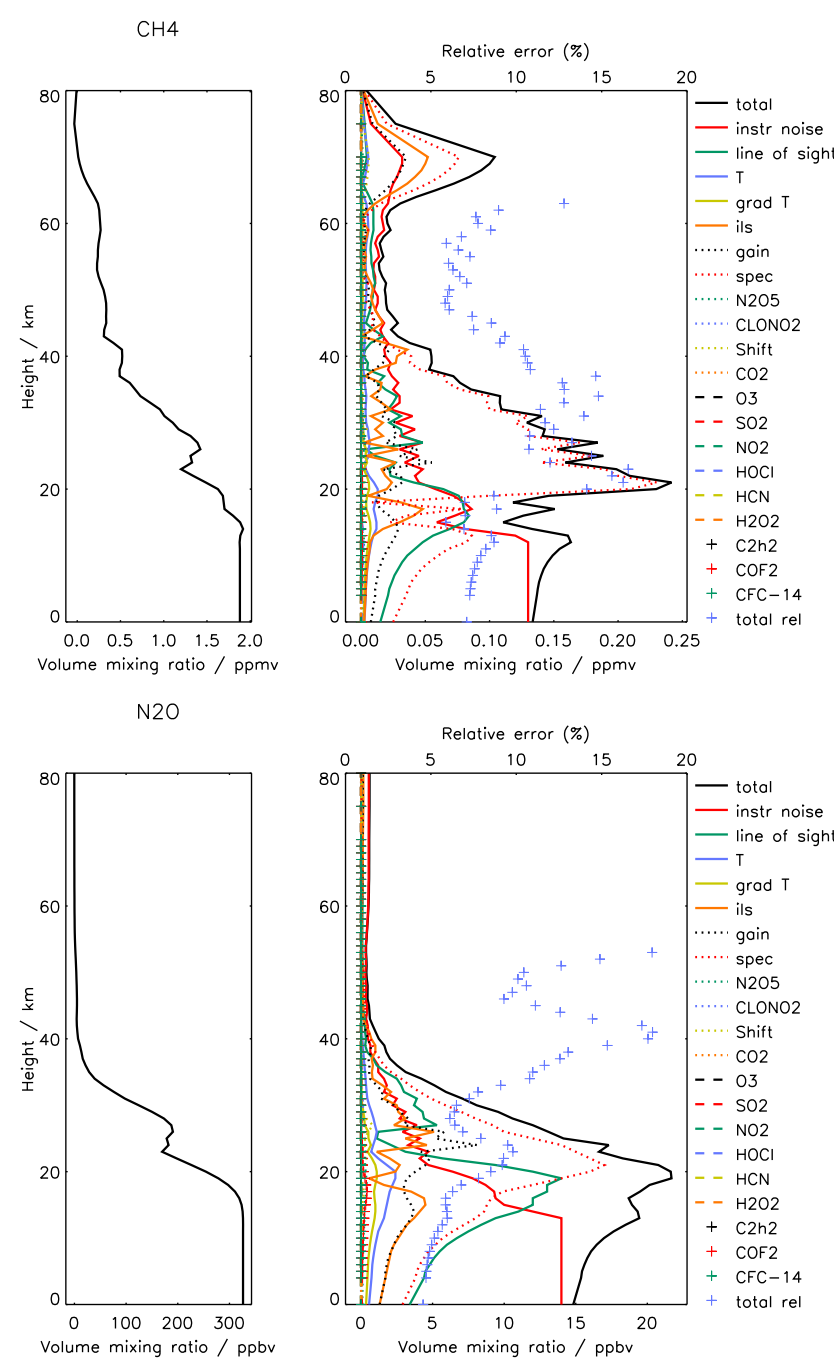

Figure 11. Estimated error contributions for the measurement in orbit 43202 at $39.4^{\circ} \mathrm{N}, 78.9^{\circ} \mathrm{E}$ on 5 June 2010, 05:02:29 UTC (derived from reduced-resolution spectra, versions V5R_CH4_224 and V5R_N2O_224). Left panels: gas profiles, right panels: contributions of different errors. All contributions are absolute values, except for the total relative error, which is given as a percentage $(\%$; upper axis). The upper panels show results for $\mathrm{CH}_{4}$; the lower panels show results for $\mathrm{N}_{2} \mathrm{O}$.

quantum number as suggested by Flaud and Piccolo (2001). Resulting line intensity uncertainties are between 2 and $5 \%$ for $\mathrm{CH}_{4}$ and between 4 and $7 \%$ for $\mathrm{NO}_{2}$ for low $J$ values. The representative uncertainties in air broadening coefficients have been estimated at $15 \%$ for $\mathrm{CH}_{4}$ and $3.5 \%$ for $\mathrm{N}_{2} \mathrm{O}$. Since no information on the error correlations between the individual transitions was available, these errors were assumed to be fully correlated, which implies that the error estimation is on the conservative side. The profiles of temperature and $\mathrm{O}_{3}$ are known from previous retrieval steps; related retrieval errors were propagated onto the $\mathrm{CH}_{4}$ and $\mathrm{N}_{2} \mathrm{O}$ results. The contribution of $\mathrm{CO}_{2}, \mathrm{SO}_{2}, \mathrm{NO}_{2}, \mathrm{HOCl}, \mathrm{HCN}$, 

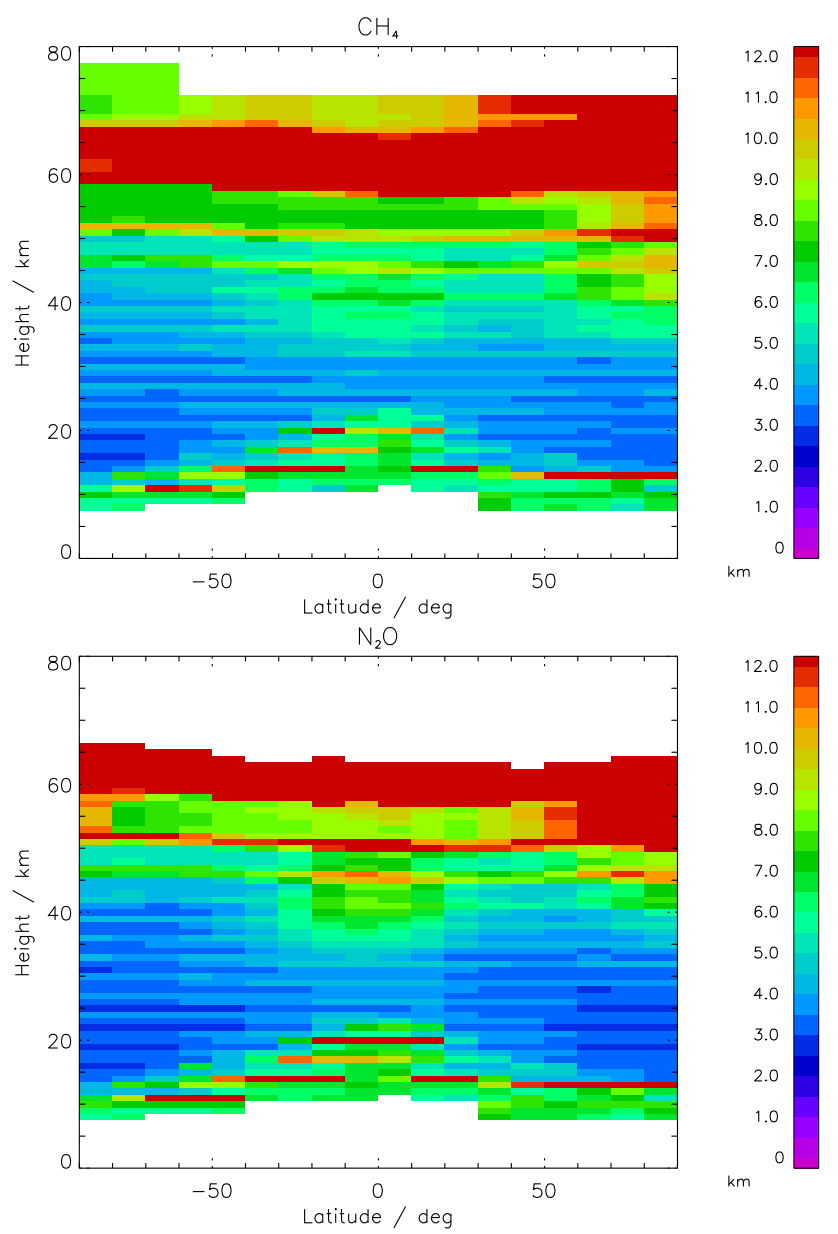

Figure 12. As Fig. 9, but for profiles from full-resolution spectra (versions V5H_CH4_21 and V5H_N2O_21).

$\mathrm{H}_{2} \mathrm{O}_{2}, \mathrm{C}_{2} \mathrm{H}_{2}, \mathrm{COF}_{2}$, CFC-14, $\mathrm{N}_{2} \mathrm{O}_{5}$ and $\mathrm{ClONO}_{2}$ to the spectra was calculated based on climatological abundances. For these gases, estimated profiles of $1 \sigma$ were used to estimate corresponding $\mathrm{CH}_{4}$ and $\mathrm{N}_{2} \mathrm{O}$ retrieval errors.

The estimated error contributions of all these sources are shown in Fig. 11 for the measurement at 5 June 2010, 05:02:29 UTC along with the derived profiles. Below $15 \mathrm{~km}$ the instrument noise is the most contributing source to the error for both gases. Above, the other errors have larger contributions. Especially the estimated spectroscopic error is very large and dominates the error budget between about 17 and $42 \mathrm{~km}$ for $\mathrm{CH}_{4}$ and between 20 and $38 \mathrm{~km}$ for $\mathrm{N}_{2} \mathrm{O}$. It has, however, to be mentioned that these spectroscopic error estimates are speculative because the inter-transition correlations of the errors are not known. The assumption of full correlations may be over-conservative. Inter-transition correlations of less than unity would lead to partial randomisation of this kind of error and the resulting uncertainty would be largely reduced. The second largest error contribution is the uncertainty of the vertical pointing of the line of sight. For $\mathrm{CH}_{4}$, below $60 \mathrm{~km}$ the relative total error is between 5 and $17 \%$.
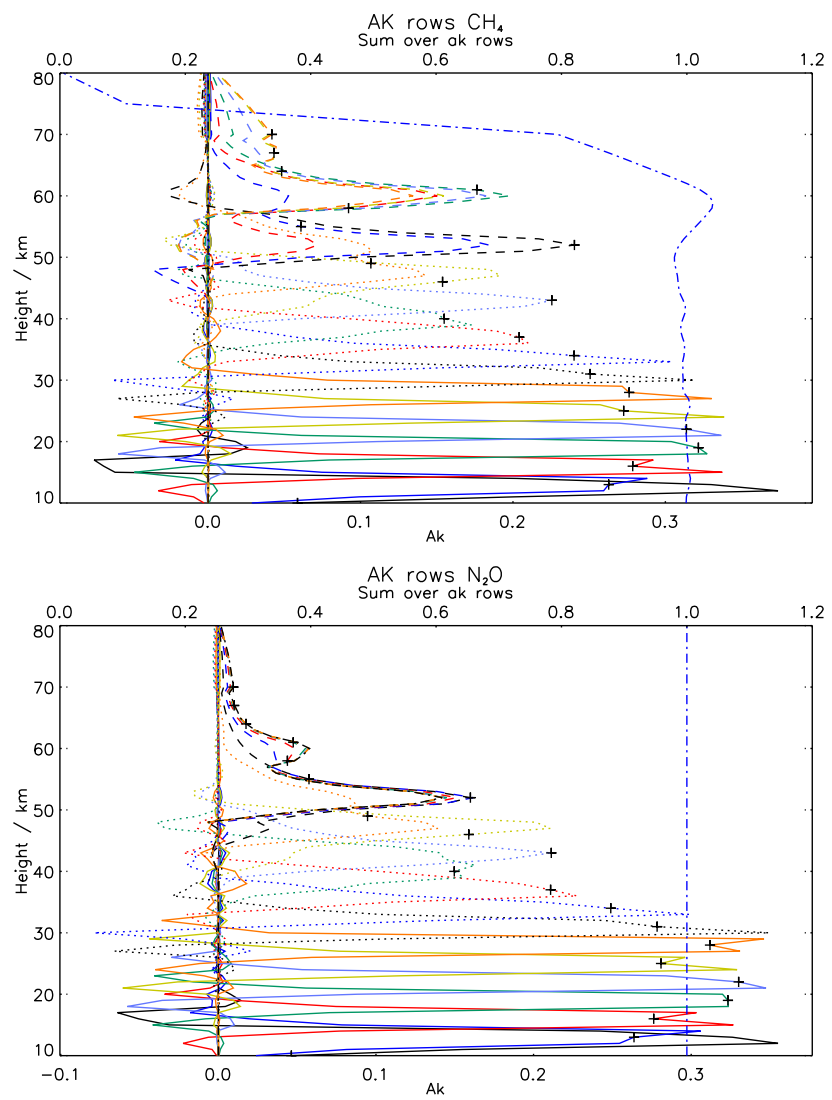

Figure 13. As Fig. 10, but for the measurement in orbit 10324 at $46.0^{\circ} \mathrm{N}, 144.5^{\circ} \mathrm{W}$ on 20 February $2004,07: 48: 31$ UTC (derived from full-resolution spectra, version V5H_CH4_21).

The relative total error of $\mathrm{N}_{2} \mathrm{O}$ below $30 \mathrm{~km}$ is around 5 to $10 \%$; above $30 \mathrm{~km}$ it increases with height to values in the order of 10 to $15 \%$, until it further increases above $40 \mathrm{~km}$. Tables 2 and 3 give numeric values for the more important error contributions for a few selected altitude grid points.

For the full-resolution spectra, oscillations in the $\mathrm{CH}_{4}$ profiles were considerably reduced in version 21 . However, a larger fraction of the retrievals did not converge $(8.50 \%$ instead of $2.78 \%$ ).

Figure 12 shows the mean vertical resolution of a test data set for the full-resolution spectra. Between 15 and $40 \mathrm{~km}$ the resolution is in the order of 3 to $6 \mathrm{~km}$ for both gases. The resolution is not as good as in the period of reduced spectral resolution, because each limb scan consists of fewer tangent altitudes.

The averaging kernels of the test measurement between 15 and $50 \mathrm{~km}$ generally look well-behaved (Fig. 13), but in some cases, particularly at very high or low altitudes, are slightly off-centre. This should be kept in mind for further interpretation of the data. In most cases the retrieved data points are most sensitive to atmospheric volume mixing ratios slightly below the altitudes they are calculated for (between 1 and $2 \mathrm{~km}$ ). The integral values of the rows show 

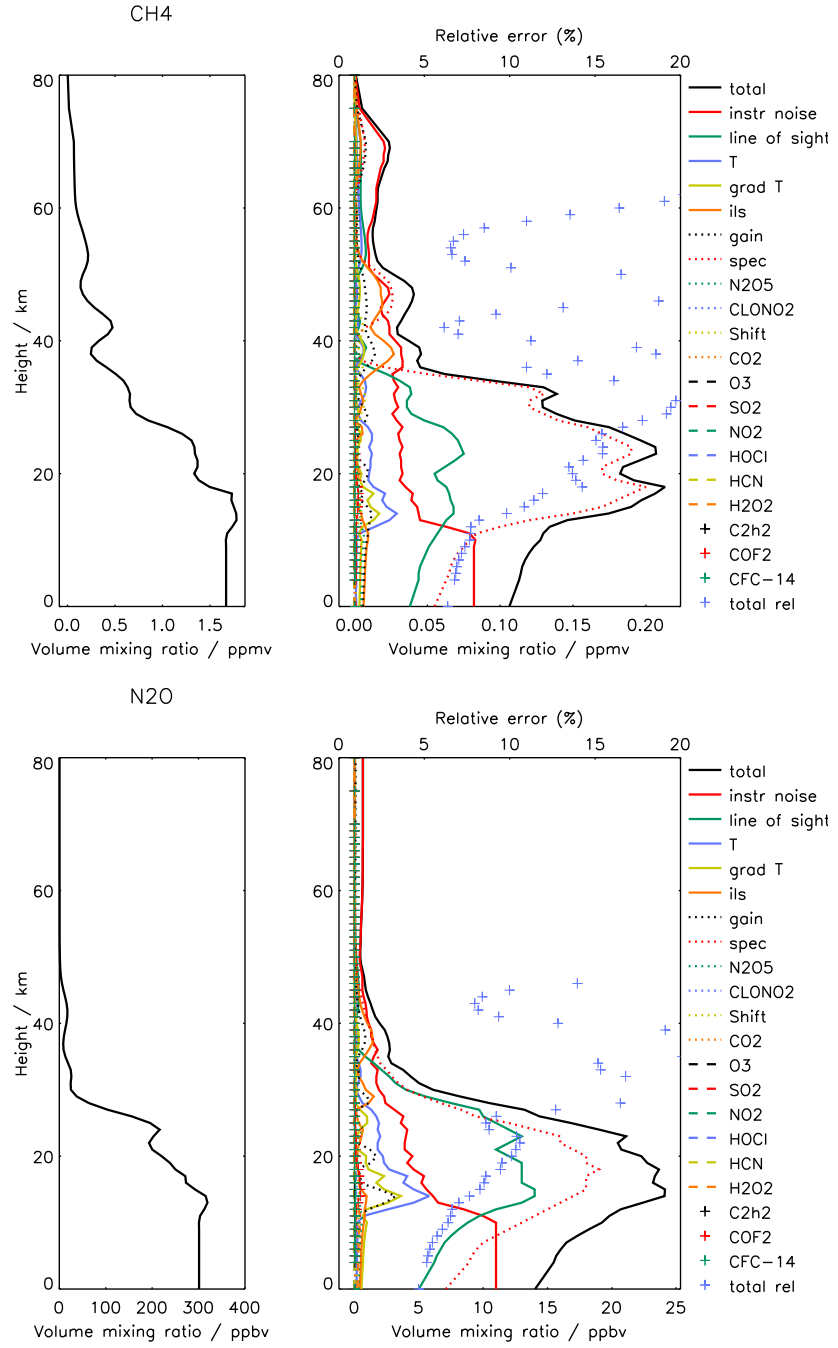

Figure 14. As Fig. 11, but for the measurement in orbit 10324 at $46.0^{\circ} \mathrm{N}, 144.5^{\circ} \mathrm{W}$ on 20 February 2004, 07:48:31 UTC (version V5H_N2O_21).

a similar behaviour as for the measurements in the lowresolution period.

The error budget shown in Fig. 14 makes clear that the instrument noise is larger than the other errors at the altitudes below $15 \mathrm{~km}$. Again the largest contributor to the error above that altitude is the spectroscopic error, followed by the uncertainty of the tangent altitude pointing (line of sight). The relative error of $\mathrm{CH}_{4}$ is between 5 and $20 \%$. For $\mathrm{N}_{2} \mathrm{O}$ it is between 5 and $10 \%$ below $25 \mathrm{~km}$ and between 5 and $20 \%$ between 25 and $45 \mathrm{~km}$. As said before, the spectroscopic error may be overestimated, because the assumption of intertransition correlations of these errors may be too pessimistic. Numeric values for certain altitude grid points and the more important error contributions are reported in Tables 4 and 5.

To estimate how representative the error analysis is, we calculated the extended error budget for additional profiles. To cover different states of the atmosphere, we used profiles
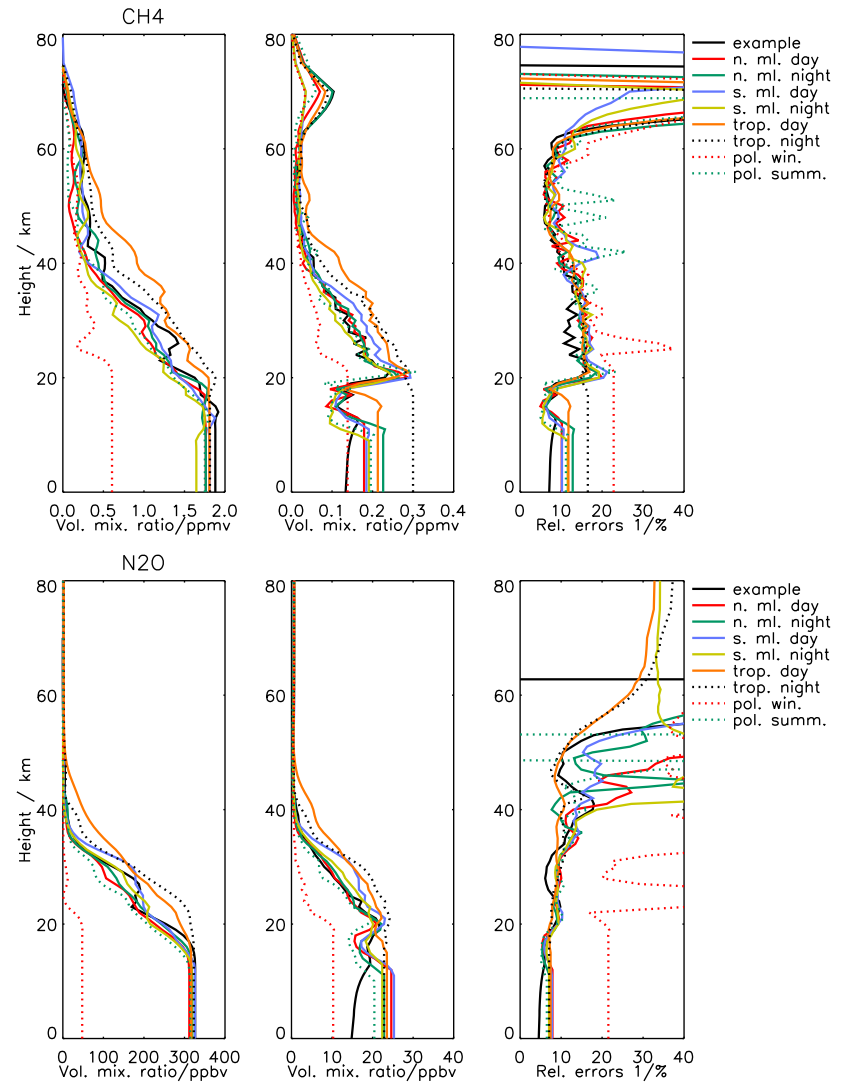

Figure 15. Profiles and total errors calculated from error budgets for different atmospheric conditions measured during the reducedresolution period. Left panels: profiles, middle panels: absolute total errors, right panels: relative total errors. The colours indicate the atmospheric conditions annotated in the legend. The black curves titled "example" are for the error budget shown in Fig. 11. The upper panels show results for $\mathrm{CH}_{4}$; the lower panels show results for $\mathrm{N}_{2} \mathrm{O}$.

in the northern and southern mid-latitudes and in the tropics, each for night and day. We also used a polar winter and a polar summer profile. For each case, we selected the profile as representative which shows the least sum of the quadratic deviations from a mean profile for that case. The total errors for these cases are shown in Fig. 15 for the reducedresolution period and in Fig. 16 for the full-resolution period. Mid-latitude errors in the lower part of the profiles are usually larger than the examples. However, most of the differences occur in areas where the profiles have no valid information. Around $20 \mathrm{~km}$ the example profiles show similar values. Between 23 and $34 \mathrm{~km}$ the example profiles for the reduced resolution have smaller relative errors than the additional error budgets; above that, the profiles show similar errors. For the low-resolution period, the example errors are, in general, similar to the errors of other mid-latitude profiles, but there are areas where either one or the other error is larger. For most cases polar winter profiles show lower ab- 
Table 2. Error budget for $\mathrm{CH}_{4}$ for the measurement in orbit 43202 at $39.4^{\circ} \mathrm{N}, 78.9^{\circ} \mathrm{E}$ on 5 June 2010, 05:02:29 UTC (derived from reducedresolution spectra, version V5R_CH4_224). Relative values are given as percentages.

\begin{tabular}{llllllllllll}
\hline $\begin{array}{l}\text { Altitude } \\
(\mathrm{km})\end{array}$ & Total & $\begin{array}{c}\text { Detector } \\
\text { noise }\end{array}$ & $\begin{array}{l}\text { Line of } \\
\text { sight }\end{array}$ & $T$ & Grad $T$ & Ils & Gain & Spectroscopy & $\mathrm{N}_{2} \mathrm{O}_{5}$ & $\mathrm{ClONO}_{2}$ & Shift \\
\hline 15 & 5.8 & 3.1 & 4.2 & 0.64 & 0.38 & 1.6 & 1.4 & 1.2 & 0.011 & 0.0025 & 0.039 \\
20 & 14 & 3.6 & 3.9 & 0.80 & 0.39 & 1.2 & 1.5 & 13 & 0.16 & 0.013 & 0.22 \\
25 & 14 & 3.4 & 0.84 & 0.48 & 0.27 & 0.31 & 2.3 & 14 & 0.18 & 0.024 & 0.31 \\
30 & 12 & 2.4 & 2.0 & 0.36 & 0.13 & 1.5 & 2.4 & 11 & 0.090 & 0.11 & 0.17 \\
40 & 11 & 3.7 & 0.38 & 0.38 & 0.011 & 5.4 & 3.5 & 7.5 & 0.19 & 0.16 & 0.23 \\
50 & 6.2 & 3.3 & 3.0 & 1.3 & 0.39 & 3.1 & 2.0 & 1.2 & 0.056 & 0.0099 & 0.089 \\
60 & 7.9 & 6.4 & 3.6 & 2.1 & 0.42 & 0.91 & 0.68 & 0.37 & 0.0087 & 0.0020 & 0.087 \\
\hline
\end{tabular}
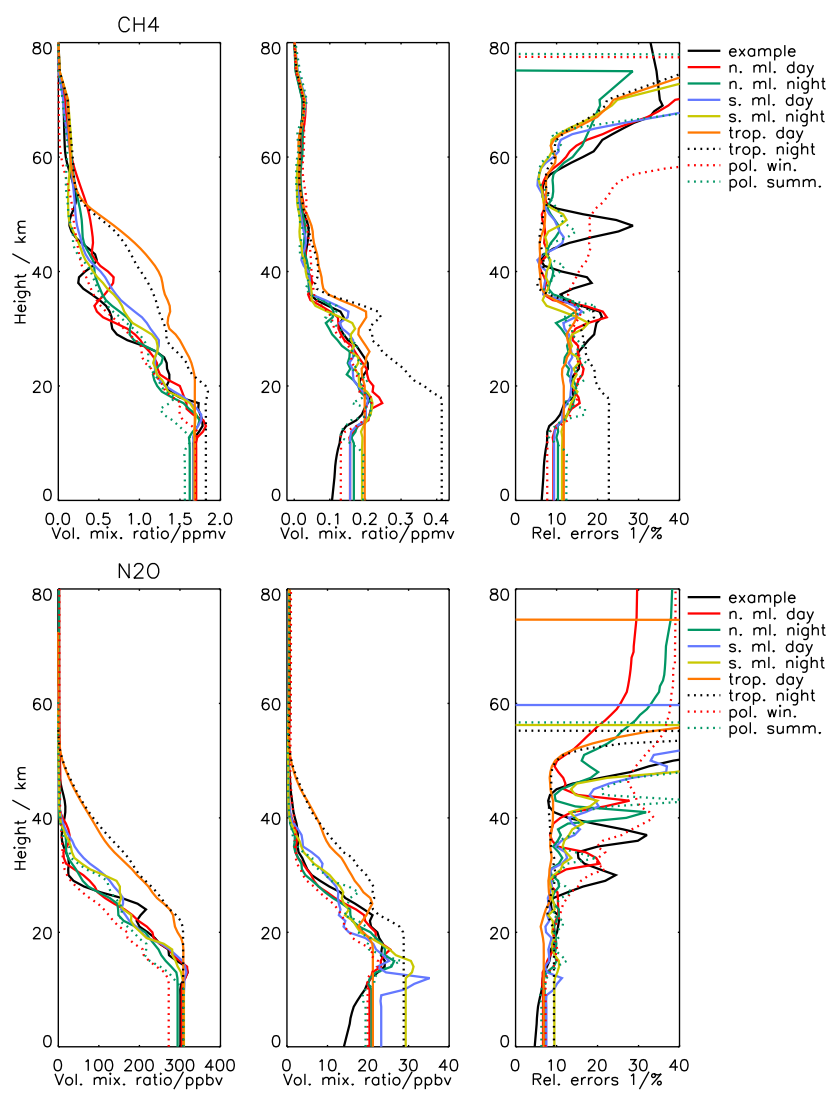

Figure 16. As Fig. 15, but for profiles measured during the fullresolution period.

solute errors, but higher relative errors than the examples, especially for the profiles in the reduced-resolution period, where those profiles are measured in the stronger southern polar vortex. Polar summer errors are similar to those in the mid-latitudes. The tropical profiles have larger errors in most cases. Exceptionally large errors due to the spectroscopic uncertainties can be found for the tropical night profile measured during the full-resolution period (Fig. 16).

The largest component of the error budget us usually the spectroscopic error (which might be overestimated as stated above). The biggest differences of the error budgets for individual profiles are usually due to the error of the pointing of the line of sight. It shows a bigger variation than the other errors. Especially sensitive is the tropopause region, where the profiles show strong changes of the gradient. Quite often, the error budget shows a spike in that region as well, which is caused by the error due to the uncertainty of the line of sight. This can be seen for example in the total error of the southern mid-latitude daytime profile for $\mathrm{N}_{2} \mathrm{O}$ for the fullresolution period.

\section{Conclusions}

The new MIPAS-ENVISAT $\mathrm{CH}_{4}$ and $\mathrm{N}_{2} \mathrm{O}$ profiles versions 21, 224 and 225 are now available for the complete MIPAS measurement period. The usage of the HITRAN 2008 spectroscopic data set improved continuum and offset handling, minor changes in the constraint, inclusion of $\mathrm{H}_{2} \mathrm{O}$ and $\mathrm{HNO}_{3}$ to the retrieval vector and different selection of spectral microwindows overall lead to improved data products where the known high bias has been reduced. Averaging kernels are found to be symmetric in the stratosphere. The vertical resolutions there are in the order of 2.5 to $7 \mathrm{~km}$ for $\mathrm{CH}_{4}, 2.5$ to $6 \mathrm{~km}$ for $\mathrm{N}_{2} \mathrm{O}$ during the reduced-resolution period and in the order of 3 to $6 \mathrm{~km}$ for both gases during the full-resolution period. The relative errors in the lower part of the profiles are mostly around $15 \%$ for $\mathrm{CH}_{4}$ and below $10 \%$ for $\mathrm{N}_{2} \mathrm{O}$. They increase above 25 or $30 \mathrm{~km}$ to values between 10 and $20 \%$, except for $\mathrm{CH}_{4}$ from the reduced-resolution period, where the error remains below $15 \%$ over almost the entire profile below $60 \mathrm{~km}$. It turned out that knowledge of the air broadening coefficients and line intensities of the individual lines is insufficient to reliably estimate the propagation of spectroscopic errors on the retrieved vmr profiles. In addition, information on the inter-transition correlations of these errors is needed. The extended error budget itself depends on the atmospheric state, hence the absolute given numbers can not be simply attributed to any other profile; but nevertheless, they give a good estimate about the general qualitative 
Table 3. As Table 2, but for $\mathrm{N}_{2} \mathrm{O}$ (version V5R_N2O_224).

\begin{tabular}{lcclllllllll}
\hline $\begin{array}{l}\text { Altitude } \\
(\mathrm{km})\end{array}$ & Total & $\begin{array}{c}\text { Detector } \\
\text { noise }\end{array}$ & $\begin{array}{l}\text { Line of } \\
\text { sight }\end{array}$ & $T$ & Grad $T$ & Ils & Gain & Spectroscopy & $\mathrm{N}_{2} \mathrm{O}_{5}$ & $\mathrm{ClONO}_{2}$ & $\mathrm{Shift}$ \\
\hline 15 & 5.9 & 3.1 & 3.7 & 0.56 & 0.31 & 1.4 & 1.1 & 2.7 & 0.074 & 0.0040 & 0.021 \\
20 & 8.6 & 2.5 & 4.7 & 0.94 & 0.43 & 0.94 & 1.5 & 6.3 & 0.13 & 0.0039 & 0.016 \\
25 & 7.8 & 2.3 & 0.62 & 0.56 & 0.29 & 1.7 & 2.9 & 6.7 & 0.15 & 0.030 & 0.16 \\
30 & 6.5 & 1.8 & 3.0 & 0.46 & 0.080 & 2.0 & 1.9 & 4.7 & 0.071 & 0.11 & 0.0071 \\
40 & 17 & 6.8 & 5.0 & 1.3 & 0.16 & 10 & 6.6 & 9.6 & 0.74 & 0.31 & 0.20 \\
50 & 10 & 8.3 & 3.3 & 0.64 & 0.18 & 3.1 & 1.8 & 3.9 & 0.045 & 0.0031 & 0.25 \\
\hline
\end{tabular}

Table 4. Error budget for $\mathrm{CH}_{4}$ for the measurement of in orbit 10324 at $46.0^{\circ} \mathrm{N}, 144.5^{\circ} \mathrm{W}$ on 20 February 2004, 07:48:31 UTC (derived from full-resolution spectra, version V5H_CH4_21). Relative values are given as percentages.

\begin{tabular}{llllllllllll}
\hline $\begin{array}{l}\text { Altitude } \\
(\mathrm{km})\end{array}$ & Total & $\begin{array}{l}\text { Detector } \\
\text { noise }\end{array}$ & $\begin{array}{c}\text { Line of } \\
\text { sight }\end{array}$ & $T$ & Grad $T$ & Ils & Gain & Spectroscopy & $\mathrm{N}_{2} \mathrm{O}_{5}$ & $\mathrm{ClONO}_{2}$ & $\mathrm{Shift}$ \\
\hline 15 & 11 & 2.5 & 3.9 & 1.3 & 0.63 & 0.13 & 0.51 & 9.7 & 0.21 & 0.027 & 0.22 \\
20 & 13 & 2.5 & 4.1 & 0.75 & 0.36 & 0.22 & 0.71 & 13. & 0.11 & 0.011 & 0.16 \\
25 & 15 & 2.4 & 5.4 & 0.92 & 0.33 & 0.077 & 0.22 & 14. & 0.15 & 0.048 & 0.27 \\
30 & 20 & 4.5 & 5.4 & 0.38 & 0.35 & 0.71 & 0.92 & 18. & 0.14 & 0.074 & 0.93 \\
40 & 11 & 8.5 & 1.6 & 1.1 & 1.5 & 6.0 & 3.3 & 0.12 & 0.23 & 0.066 & 1.1 \\
50 & 17 & 8.1 & 1.9 & 0.44 & 1.5 & 8.1 & 3.5 & 11 & 0.13 & 0.0040 & 0.74 \\
60 & 17 & 15 & 4.8 & 3.5 & 0.070 & 1.5 & 1.2 & 1.2 & 0.0011 & 0.0056 & 0.35 \\
\hline
\end{tabular}

Table 5. As Table 4, but for $\mathrm{N}_{2} \mathrm{O}$ (version V5H_N2O_21).

\begin{tabular}{llllllllllll}
\hline $\begin{array}{l}\text { Altitude } \\
(\mathrm{km})\end{array}$ & Total & $\begin{array}{l}\text { Detector } \\
\text { noise }\end{array}$ & $\begin{array}{l}\text { Line of } \\
\text { sight }\end{array}$ & $T$ & $\mathrm{Grad} T$ & $\mathrm{Ils}$ & Gain & Spectroscopy & $\mathrm{N}_{2} \mathrm{O}_{5}$ & $\mathrm{ClONO}_{2}$ & $\mathrm{Shift}$ \\
\hline 15 & 8.2 & 1.9 & 4.8 & 1.6 & 0.79 & 0.17 & 0.65 & 6.2 & 0.16 & 0.058 & 0.13 \\
20 & 10 & 2.0 & 5.4 & 1.0 & 0.41 & 0.11 & 0.77 & 8.2 & 0.082 & 0.011 & 0.020 \\
25 & 8.2 & 1.8 & 5.6 & 0.97 & 0.51 & 0.16 & 0.16 & 6.1 & 0.082 & 0.0072 & 0.17 \\
30 & 24 & 7.6 & 16 & 0.56 & 0.80 & 3.5 & 1.2 & 16 & 0.068 & 0.032 & 0.056 \\
40 & 13 & 7.2 & 0.085 & 0.24 & 1.2 & 6.6 & 3.9 & 7.2 & 0.048 & 0.0085 & 0.60 \\
50 & 39 & 34 & 12 & 0.94 & 1.1 & 6.8 & 3.3 & 10 & 0.11 & 0.059 & 0.33 \\
\hline
\end{tabular}

nature of the errors discussed. Comparisons to other instruments will be the subject of an upcoming paper.

Acknowledgements. This work is a contribution to the "Helmholtz Climate Initiative REKLIM" (Regional Climate Change), a joint research project of the Helmholtz Association of German research centres (HGF). We thank ESA for providing the MIPAS level-1b data.

We acknowledge support by Deutsche Forschungsgemeinschaft and Open Access Publishing Fund of Karlsruhe Institute of Technology.

The article processing charges for this open-access publication were covered by a Research Centre of the Helmholtz Association.

Edited by: M. Riese

\section{References}

Alvarado, M. J., Payne, V. H., Cady-Pereira, K. E., Hegarty, J. D., Kulawik, S. S., Wecht, K. J., Worden, J. R., Pittman, J. V., and Wofsy, S. C.: Impacts of updated spectroscopy on thermal infrared retrievals of methane evaluated with HIPPO data, Atmos. Meas. Tech., 8, 965-985, doi:10.5194/amt-8-965-2015, 2015.

Bardeen, C. G., Toon, O. B., Jensen, E. J., Marsh, D. R., and Harvey, V. L.: Numerical simulations of the three-dimensional distribution of meteoric dust in the mesosphere and upper stratosphere, J. Geophys. Res., 113, d17202, doi:10.1029/2007JD009515, 2008.

Beer, R., Glavich, T. A., and Rider, D. M.: Tropospheric emission spectrometer for the Earth Observing System's Aura satellite, Appl. Optics, 40, 2356-2367, 2001.

Fischer, H., Birk, M., Blom, C., Carli, B., Carlotti, M., von Clarmann, T., Delbouille, L., Dudhia, A., Ehhalt, D., Endemann, M., Flaud, J. M., Gessner, R., Kleinert, A., Koopman, R., Langen, J., López-Puertas, M., Mosner, P., Nett, H., Oelhaf, H., Perron, G., Remedios, J., Ridolfi, M., Stiller, G., and Zander, R.: MIPAS: an 
instrument for atmospheric and climate research, Atmos. Chem. Phys., 8, 2151-2188, doi:10.5194/acp-8-2151-2008, 2008.

Flaud, J.-M. and Piccolo, C.: Spectroscopic Database updates, Tech. Rep. TN-LPM-IROE-01, Issue 1, Appendix 3, Laboratoire de physique des matériaux (LPM) - CNRS, Nancy and Istituto Ricerca Onde Elettromagnetiche (IROE) - CNR, Florence, 2001.

Glatthor, N., von Clarmann, T., Fischer, H., Funke, B., Grabowski, U., Höpfner, M., Kellmann, S., Kiefer, M., Linden, A., Milz, M., Steck, T., Stiller, G. P., Mengistu Tsidu, G., and Wang, D. Y.: Mixing processes during the Antarctic vortex split in September/October 2002 as inferred from source gas and ozone distributions from ENVISAT-MIPAS, J. Atmos. Sci., 62, 787-800, 2005.

Höpfner, M., von Clarmann, T., Engelhardt, M., Fischer, H., Funke, B., Glatthor, N., Grabowski, U., Kellmann, S., Kiefer, M., Linden, A., López-Puertas, M., Milz, M., Steck, T., Stiller, G. P., Wang, D. Y., Ruhnke, R., Kouker, W., Reddmann, T., Bernath, P., Boone, C., and Walker, K. A.: Comparison between ACEFTS and MIPAS IMK/IAA profiles of $\mathrm{O}_{3}, \mathrm{H}_{2} \mathrm{O}, \mathrm{N}_{2} \mathrm{O}, \mathrm{CH}_{4}$, CFC-11, CFC-12, $\mathrm{HNO}_{3}, \mathrm{ClONO}_{2}, \mathrm{NO}_{2}, \mathrm{~N}_{2} \mathrm{O}_{5}, \mathrm{CO}$, and $\mathrm{SF}_{6}$ in February/March 2004, in: Proc. Third Workshop on the Atmospheric Chemistry Validation of Envisat, (ACVE-3), 4-7 December 2006, Esrin, Frascati, Italy, vol. ESA SP-642, CD-ROM, ESA Publications Division, ESTEC, Noordwijk, the Netherlands, 2007.

Kleinert, A., Aubertin, G., Perron, G., Birk, M., Wagner, G., Hase, F., Nett, H., and Poulin, R.: MIPAS Level 1B algorithms overview: operational processing and characterization, Atmos. Chem. Phys., 7, 1395-1406, doi:10.5194/acp-7-13952007, 2007.

Laeng, A., Plieninger, J., von Clarmann, T., Grabowski, U., Stiller, G., Eckert, E., Glatthor, N., Haenel, F., Kellmann, S., Kiefer, M., Linden, A., Lossow, S., Deaver, L., Engel, A., Hervig, M., Levin, I., McHugh, M., Noël, S., Toon, G., and Walker, K.: Validation of MIPAS IMK/IAA methane profiles, Atmos. Meas. Tech. Discuss., 8, 5565-5590, doi:10.5194/amtd-8-5565-2015, 2015.

Neely III, R. R., English, J. M., Toon, O. B., Solomon, S., Mills, M., and Thayer, J. P.: Implications of extinction due to meteoritic smoke in the upper stratosphere, Geophys. Res. Lett., 38, L24808, doi:10.1029/2011GL049865, 2011.

Norton, H. and Beer, R.: New apodizing functions for Fourier spectrometry, J. Opt. Soc. Am, 66, 259-264 (Errata J. Opt. Soc. Am., 67, 419, 1977), 1976.

Rodgers, C. D.: Inverse Methods for Atmospheric Sounding: Theory and Practice, in: vol. 2 of Series on Atmospheric, Oceanic and Planetary Physics, edited by: Taylor, F. W., World Scientific, Singapore, New Jersey, London, Hong Kong, 2000.
Rothman, L. S., Jacquemart, D., Barbe, A., Benner, D. C., Birk, M., Brown, L. R., Carleer, M. R., Chackerian Jr., C., Chance, K., Coudert, L. H., Dana, V., Devi, V. M., Flaud, J.-M., Gamache, R. R., Goldman, A., Hartmann, J.-M., Jucks, K. W., Maki, A. G., Mandin, J.-Y., Massie, S. T., Orphal, J., Perrin, A., Rinsland, C. P., Smith, M. A. H., Tennyson, J., Tolchenov, R. N., Toth, R. A., Vander Auwera, J., Varanasi, P., and Wagner, G.: The HITRAN 2004 molecular spectroscopic database, J. Quant. Spectrosc. Ra., 96, 139-204, doi:10.1016/j.jqsrt.2004.10.008, 2005.

Rothman, L. S., Gordon, I. E., Barbe, A., Benner, D. C., Bernath, P. F., Birk, M., Brown, L. R., Boudon, V., Champion, J. P., Chance, K. V., Coudert, L. H., Dana, V., Devi, M. V., Fally, S., Flaud, J. M., Gamache, R. R., Goldman, A., Jacquemart, D., Lacome, N., Mandin, J. Y., Massie, S. T., Mikhailenko, S., Nikitin, A., Orphal, J., Perevalov, V., Perrin, A., Rinsland, C. P., Ŝimeĉková, M., Smith, M. A. H., Tashkun, S., Tennyson, J., Toth, R. A., Vandaele, A. C., and der Auwera, J. V.: The HITRAN 2008 molecular spectroscopic database, J. Quant. Spectrosc. Ra., 110, 533-572, 2009.

Steck, T. and von Clarmann, T.: Constrained profile retrieval applied to the obervation mode of the Michelson Interferometer for Passive Atmospheric Sounding, Appl. Optics, 40, 3559-3571, 2001.

Tikhonov, A.: On the solution of incorrectly stated problems and method of regularization, Dokl. Akad. Nauk. SSSR, 151, 501504, 1963.

von Clarmann, T. and Echle, G.: Selection of optimized microwindows for atmospheric spectroscopy, Appl. Optics, 37, 76617669, 1998.

von Clarmann, T., Glatthor, N., Grabowski, U., Höpfner, M., Kellmann, S., Kiefer, M., Linden, A., Mengistu Tsidu, G., Milz, M., Steck, T., Stiller, G. P., Wang, D. Y., Fischer, H., Funke, B., Gil-López, S., and López-Puertas, M.: Retrieval of temperature and tangent altitude pointing from limb emission spectra recorded from space by the Michelson Interferometer for Passive Atmospheric Sounding (MIPAS), J. Geophys. Res., 108, 4736, doi:10.1029/2003JD003602, 2003.

von Clarmann, T., Höpfner, M., Kellmann, S., Linden, A., Chauhan, S., Funke, B., Grabowski, U., Glatthor, N., Kiefer, M., Schieferdecker, T., Stiller, G. P., and Versick, S.: Retrieval of temperature, $\mathrm{H}_{2} \mathrm{O}, \mathrm{O}_{3}, \mathrm{HNO}_{3}, \mathrm{CH}_{4}, \mathrm{~N}_{2} \mathrm{O}, \mathrm{ClONO}_{2}$ and $\mathrm{ClO}$ from MIPAS reduced resolution nominal mode limb emission measurements, Atmos. Meas. Tech., 2, 159-175, doi:10.5194/amt-2-159-2009, 2009 . 